\section{Pacific Northwest}

National Laboratory

Operated by Battelle for the

U.S. Department of Energy

\title{
PHASE 1 Technical Letter Report - TS-00358: Portable Acoustic Contraband Detector
}

AA Diaz

July 2007

Prepared for U.S. Navy Office of Naval Research, U.S. Naval Forces Central Command, and Department of the Navy, under Contract DE-AC05-76RL01830

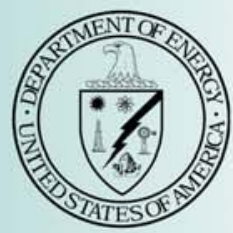




\title{
DISCLAIMER
}

This report was prepared as an account of work sponsored by an agency of the United States Government. Neither the United States Government nor any agency thereof, nor Battelle Memorial Institute, nor any of their employees, makes any warranty, express or implied, or assumes any legal liability or responsibility for the accuracy, completeness, or usefulness of any information, apparatus, product, or process disclosed, or represents that its use would not infringe privately owned rights. Reference herein to any specific commercial product, process, or service by trade name, trademark, manufacturer, or otherwise does not necessarily constitute or imply its endorsement, recommendation, or favoring by the United States Government or any agency thereof, or Battelle Memorial Institute. The views and opinions of authors expressed herein do not necessarily state or reflect those of the United States Government or any agency thereof.

\author{
PACIFIC NORTHWEST NATIONAL LABORATORY \\ operated by \\ BATTELLE \\ for the \\ UNITED STATES DEPARTMENT OF ENERGY \\ under Contract DE-AC05-76RL01830
}

Printed in the United States of America
Available to DOE and DOE contractors from the Office of Scientific and Technical Information,
P.O. Box 62, Oak Ridge, TN 37831-0062;
ph: (865) 576-8401
fax: $(865) 576-5728$
email: reports@adonis.osti.gov

\begin{abstract}
Available to the public from the National Technical Information Service, U.S. Department of Commerce, 5285 Port Royal Rd., Springfield, VA 22161 ph: (800) 553-6847 fax: (703) 605-6900

email: orders $@$ ntis.fedworld.gov

online ordering: http://www.ntis.gov/ordering.htm
\end{abstract}




\title{
PHASE 1 Technical Letter Report -
} TS-00358: Portable Acoustic Contraband Detector

\author{
A. A. Diaz
}

July 2007

Prepared for

U.S. Navy Office of Naval Research,

U.S. Naval Forces Central Command, and

Department of the Navy,

under Contract DE AC05 76RL01831

Pacific Northwest National Laboratory

Richland, Washington 99352 



\section{Executive Summary}

The Space and Naval Warfare Systems Center San Diego (SSCSD) is currently leading a U.S. Navy Office of Naval Research (ONR), TechSolutions Project that is focused on research, development, testing, evaluation and transfer of an existing and maturing portable acoustic contraband detector (PACD) technology and associated acoustic signatures, for liquids of interest in a military maritime interception operations (MIO) environment. The U.S. Navy has performed preliminary operational testing/evaluation of the PACD technology for visit, board, search, and seizure (VBSS) operations in the U.S. Naval Forces Central Command (NAVCENTCOM) area of responsibility (AOR). The Pacific Northwest National Laboratory (PNNL), a U.S. Department of Energy Federally Funded Research and Development Center, is the developer of the original commercially available Product Acoustic Signature System (PASS) detector for this project, and has continued involvement in research and development of the device since the early 2000s. SSCSD is pursuing technical advancements and eventual transfer of military-specific PASS technologies to be developed by PNNL in support of the ONR TechSolutions project TS-00358: Portable Acoustic Contraband Detector - PACD, Phase 1. The technical scope of this effort focuses on the development, testing and transfer of technology (e.g., acoustic liquids signature data, software and hardware) between PNNL and SSCSD for the overall objective of enhancing the commercially available PASS detector for effective deployment and use in a military MIO environment. This technical letter report (TLR) describes the Phase 1 activities managed and conducted by PNNL in support of this effort.

Primary Phase 1 technical activities conducted by PNNL included an effort to address critical deficiencies associated with the performance and ease of use of the PASS unit and to provide an enhanced capability to identify materials (liquids) of interest to the military in the MIO environment AOR. Through a subcontract with the commercial manufacturer and licensee of PASS, Spearhead Innovations, Inc. (SI) and their sister company responsible for manufacturing of the device, International Engineering \& Manufacturing (IE\&M), an effort was conducted to improve performance and ease of use for operators of the device. Software and hardware issues were identified in May 2006 field operational testing in Bahrain, conducted by the NAVCENTCOM Science Advisor. As a result, refinements and improvements that would be advantageous to system operators were targeted in Phase 1 of this effort. Some of these activities were addressed in Phase 1 as part of this PNNL effort and associated subcontract with SI, while other Phase 1 (and Phase 2) enhancements are being addressed under a separate contractual agreement between SI-IE\&M and SSCSD, and will be reported separately/are not described in this TLR. The PNNL effort described in this Phase 1 TLR included eliminating occasional software crashes, providing a battery power indicator for the sensor and improving visibility of the PDA screen in bright conditions. In addition, a separate activity was initiated to enhance the PASS acoustic signature liquids database for improved liquid identification and classification performance. This database is the foundation for improving the functionality and capabilities of the PASS for the military MIO environment, and consisted of acoustic characterization of a specific number of liquids as a function of temperature. Using a PNNL-developed automated liquid characterization system, 22 liquid commodities were acoustically characterized and speed-of-sound profiles as a function of temperature were recorded, uploaded to the device and tested. This activity included conducting a set of in-lab validation tests to verify the resultant performance of the hand-held PASS device with the database values on a suite of containers and liquids over a range of temperatures. Finally, Phase 1 activities were completed with a final Go/No-Go training, performance demonstration (PD) and operational testing and evaluation (OT\&E) activity hosted at the U.S. Department of Energy Volpentest Hazardous Materials Management and 
Emergency Response (HAMMER) Training \& Education Center on the Hanford Nuclear Reservation. This final task included hosting the ONR TechSolutions Program Manager, both the former and current NAVCENTCOM Science Advisors, and Military Technology Evaluation Personnel from the ONR Naval Reserve Unit (P38) to Richland, Washington, for the PD/OT\&E exercise. Members of the technical team from PNNL, SSCSD, and SI-IE\&M designed a PD/OT\&E plan for the exercise to provide OT\&E criteria that would adequately address all Phase 1 enhancements to the PASS detector, provide a robust performance evaluation for the expected operational environment, and maximize the enhanced PASS unit hands-on time by OT\&E participants. The finalized OT\&E plan and agenda are being provided to the client under separate cover, while the list of attendees is included in Appendix E.

This TLR provides the results of all PNNL-managed activities on this project, and contains a description of the data acquisition configuration and testing protocols, results and conclusions from this work. This TLR is part of the final deliverables package submitted to the client during the Phase 1 Go/No-Go meeting in Richland, Washington, on July 31, 2007. 


\section{Abbreviations, Acronyms, and Glossary}

AIP

$\mathrm{AL}$

AOR

DOE

FFRDC

GUI

HAMMER

HDPE

IE\&M

MIO

MSDS

NAVCENTCOM

ONR

OSHA

OT\&E

PACD

PASS

PD

PEL

PNNL

POVM

SI

SOP

SSCSD

STEL

TLR

TLV

TS

TWA

VBSS

VCS
American Institute of Physics

action level

area of responsibility

U.S. Department of Energy

Federally Funded Research and Development Center

graphical user interface

Hazardous Materials Management and Emergency Response

high density poly ethylene

International Engineering \& Manufacturing

maritime interception operations

Material Safety Data Sheet

U.S. Naval Forces Central Command

U.S. Navy Office of Naval Research

Occupational Safety and Health

operational testing and evaluation

portable acoustic contraband detector

Product Acoustic Signature System

performance demonstration

permissible exposure level

Pacific Northwest National Laboratory

passive organic vapor monitors

Spearhead Innovations, Inc.

standard operating procedure

Space and Naval Warfare Systems Center San Diego

short-term exposure limit

technical letter report

total level of volatiles

TechSolutions

time weighted average

visit, board, search, and seizure

Velocity Characterization System 


\section{Contents}

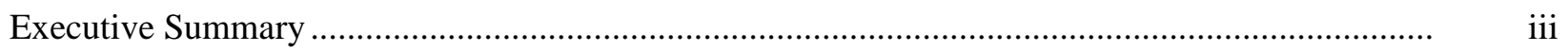

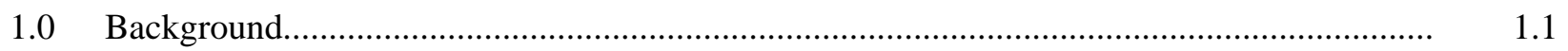

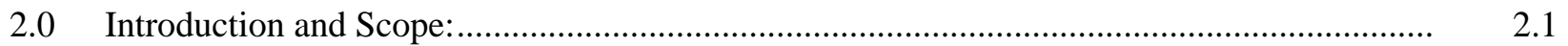

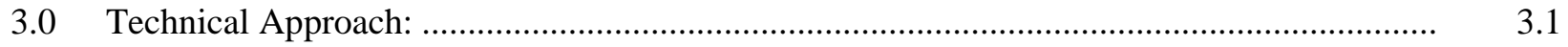

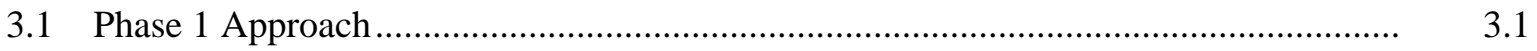

3.1.1 PNNL Task 1 - Improve Performance and Ease of Use for Operator .............. 3.1

3.1.2 PNNL Task 2 - Enhance Acoustic Signature Database for Military Use ......... 3.2

3.1.3 PNNL Task 3 - Optest/Performance Evaluation and Support .......................... 3.3

4.0 PASS Database Generation System: The Velocity Characterization System .......................

4.1 Principles of Operation for Liquid Acoustic Velocity Measurements .......................... 4.1

4.2 Mechanical Design Features and Operation Principles of the VCS:.............................. $\quad 4.4$

4.3 Location, Safety and General Process of Database Generation Measurements

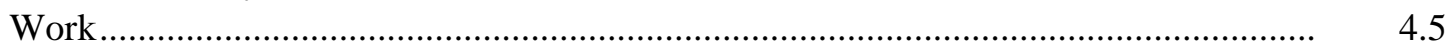

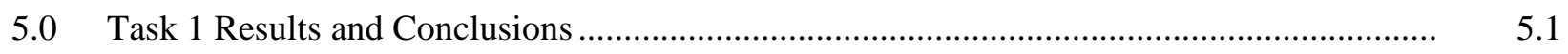

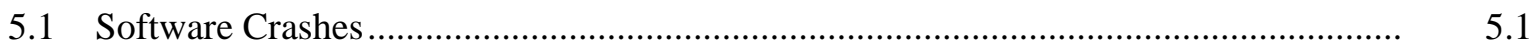

5.2 Battery Power Indicator........................................................................................

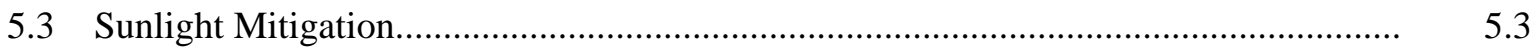

5.3.1 Testing in Bright Sunlight ............................................................................ 5.3

5.3.2 Approach ................................................................................................. 5.3

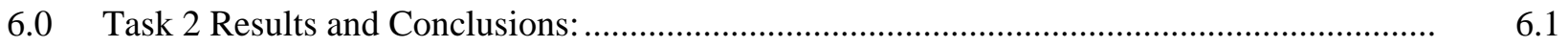

6.1 Acoustic Characterization of Liquids:...................................................................... 6.1

6.2 Industrial Hygiene (IH) Monitoring Results of VCS Liquids: ...................................... 6.2

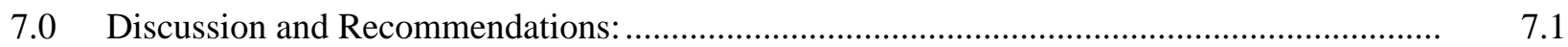

8.0 PNNL Management and Technical Points of Contact:..........................................................

Appendix A - List of Liquids Chosen for Acoustic Characterization in the PHASE 1 PACD Database

Appendix B - Excel Plots Illustrating the Acoustic Velocity-Temperature Profiles for Each Liquid

Appendix C - Final PHASE 1 Database Listing of Liquids and Associated 2nd Order Polynomial

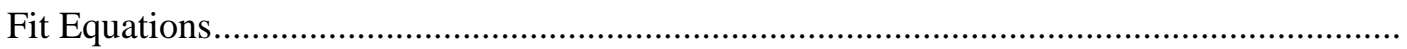

Appendix D - Excel Plots of Database Validation Data on Subset of Liquids for Various Containers Across Multiple Temperature Points............................................................. D. D

Appendix E - List of Clients and Participants in Final Phase 1 Activities For TS-00358 ............... E.1 


\section{Figures}

4.1 VCS System at PNNL Used for Database Generation for PASS ...........................................

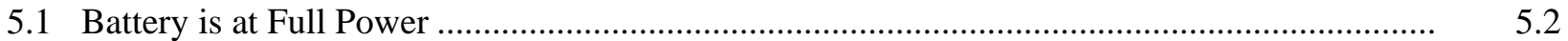

5.2 Battery No Longer Supports System Operation .......................................................................

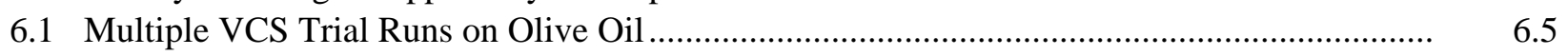

6.2 Published Velocity-Temperature Profile for Pure Water Compared with VCS-Generated

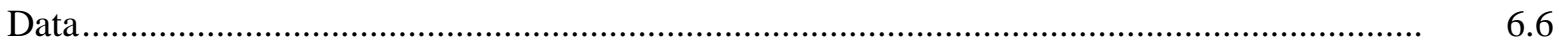

6.3 Composite Plot of all 22 Liquids Illustrating Acoustic Velocity as a Function of Temperature

7.1 Example Data Acquired on Water in Two Different Sized Containers, a Stainless Steel 55-Gallon Drum and a 2.5-Gallon Stainless Steel Container.

\section{Tables}

6.1 Industrial Hygiene Monitoring Results for Various Organic Solvents Characterized by VCS.

6.4

6.2 Results from Evaluation of VCS Precision for Various Liquids

6.3 Comparison of Results from Evaluation of VCS Accuracy for Water Based Upon a Comparative Evaluation of Published Data in the Literature and VCS Measured Data on Pure Water. 


\subsection{Background}

The Product Acoustic Signature System (PASS) platform was initially developed for First Responders, Customs Inspectors and Law-Enforcement personnel where a need for a portable, batteryoperated, hand-held system for real-time, sealed-container inspection and contents (liquid/material) identification is required. Military end-users (such as Navy visit, board, search, and seizure [VBSS] teams) have a need for employing advanced technologies to address issues such as identification, confirmation or classification of substances and materials (CW agents, hazardous/flammable liquids, liquid explosives, etc.) in sealed containers, during field and first response operations, both noninvasively and nondestructively. Also of primary importance is the capability to identify and/or detect illicit drugs, contraband, and precursor chemicals used in the fabrication of illicit materials, such as illicit drugs or chemical weapons agents.

The most common approach today is to physically collect a discrete sample of the contents of a container and perform a field or laboratory analysis of that sample that can be very time-consuming and costly. Opening sealed containers of unknown origin is dangerous and can expose individuals to a host of potential hazards, requiring suits and costly precautions while endangering field personnel. X-ray technologies are often quite costly, bulky, inadequate (in their ability to identify liquid contents), and impractical for immediate response scenarios. Commercially available technologies that claim to provide these types of capabilities often do not have the appropriate measurement sensitivity, are not field hardened, have insufficient reliability (high false alarms), require a high level of expertise for operation, and/or are not suitable for the wide variety of containers and liquids/materials that are encountered in the field.

The PASS technical approach employs an advanced, state-of-the-art, acoustic measurement method for non-invasive sealed-container inspection and contents identification/classification. This measurement methodology is based upon many years of experience and fundamental scientific research in measuring an acoustic physical property measurement (as a signature or fingerprint for identification/classification of liquids/solids) using nondestructive and non-invasive means for acquiring information through a solid material or liquid-filled sealed container. The PASS technology employs ultrasonic technology to accurately measure the acoustic velocity (speed of sound) in a fluid to: (1) detect anomalies, contraband and hidden compartments in liquid-filled containers and solid form commodities; (2) sort/classify liquid types into groups of like and unlike; (3) identify liquids and bulk-solids as a function of temperature, and; (4) determine the fill-level in liquid-filled containers. 


\subsection{Introduction and Scope}

This effort is focused on providing an enhanced, robust, portable acoustic detection capability directed at nondestructively identifying/classifying liquids, and detecting contraband in cargo/materials containers, without a need for opening the container, in a maritime interception operations (MIO) environment. The earlier commercially available version of this detector technology currently has both operational and technical limitations associated with its use in a harsh maritime environment and operation by non-technical personnel. It was originally designed to interrogate cargo materials, but with a somewhat different cargo/materials focus and in a much different operational environment. This effort seeks to optimize the detector for use in the MIO environment by simplifying the software graphical user interface; providing enhanced user friendliness and capabilities; enhanced detection reproducibility, consistency and minimized risk for false positives; and increased in-field performance of the detector. The optimized unit will also detect and identify an expanded suite of material acoustic signatures prevalent in the MIO environment. These capabilities will provide personnel/users of the detector a significantly more reliable method of screening cargo/materials for different types of contraband items of potential concern that might be hidden in cargo/materials containers. This project is separated into two phases of effort. Phase 1 is directed at enhancing the unit to specifically address critical detector deficiencies as noted in the initial evaluation of the commercial acoustic detector unit (PASS) during operational testing (Bahrain, May 2006). These enhancements would further enhance PASS performance, increase its user-friendliness, and provide a military AOR-specific acoustic signature database consisting of $\sim 15-20$ liquid constituents. Phase 2 will focus on further ruggedization of the detector and the continued development of the acoustic signature database with the addition of 5-10 new liquid constituents. 
2.2 


\subsection{Technical Approach}

The work described here defines work conducted by Pacific Northwest National Laboratory (PNNL) and its subcontractor (Spearhead Innovations, Inc. [SI]), providing technical support to efforts directed at enhancing and improving the performance and robustness of the PASS to nondestructively identify/classify liquids and detect contraband in cargo/materials containers, without a need for opening the container, in a MIO environment.

\subsection{Phase 1 Approach}

This phase of the effort consisted of activities focused on operator features and optimizing operational capabilities and functionality of the PASS unit for use in an arid maritime operational environment, and addressing critical deficiencies associated with the performance and ease of use of the PASS unit itself. This work also provides an enhanced capability to identify materials of interest to the military in the maritime operational area of responsibility (AOR). PNNL Tasks 1, 2 and 3 correspond to tasks indicated parenthetically below as specified in the original overall TechSolutions (TS) project execution plan that included all of the technical and programmatic PNNL, Spearhead Innovations, Inc.-International Engineering \& Manufacturing (SI-IE\&M), and Space and Naval Warfare Systems Center San Diego (SSCSD) tasking.

\subsubsection{PNNL Task 1 (TS 2.0). Improve Performance and Ease of Use for Operator (Spearhead Innovations, Inc. - Subcontractor to PNNL)}

The following software and hardware subtasks were identified in the May 2006 field optesting in Bahrain as refinements and improvements that would be advantageous to system operators.

\section{PNNL Subtask 1.1 (TS 2.1) - Eliminate occasional software crashes}

The PASS software is susceptible to crash, especially when the inspection button remains depressed for an extended time. Under this task, the software was heavily tested to replicate crashes, determine the cause(s) of crashes, and correct causal deficiencies. Particular attention was paid to the module of software that accepts data transmission from the sensor and to other parts of the software that interface with that module. Efforts included investigation into whether data buffer overflow is prevalent when the software reads off the network device. Also, this subtask investigated whether the newer version of the iPAQ ${ }^{\circledR}$ operating platform software introduced additional crash risks and modifications to the PASS software were addressed appropriately.

\section{PNNL Subtask 1.2 (TS 2.2) - Provide battery power indicator for sensor}

PASS software receives data from the sensor that contains a field with information about the sensor's battery power; the software was modified to extract and use that data. This effort focused on extracting that data and designing/coding changes to the graphical user interface (GUI) to add the desired indicator to the operational menu of the PASS. 


\section{PNNL Subtask 1.3 (TS 2.5) - Improve visibility of PDA screen in bright conditions}

This task evaluated and applied options for adapting a filter or other device to make the PDA display easier to read in bright sunlight and was completed via activities to assemble, test and apply the most effective solution.

\subsubsection{PNNL Task 2 (TS 3.0). Enhance Acoustic Signature Database for Military Use (PNNL)}

This work consists of providing a military AOR-specific database consisting of 15-20 additional liquid constituents to the list of PASS liquid commodities with full acoustic velocity profiles as a function of temperature.

PNNL Subtask 2.1 (TS 3.1). Identify/interrogate suite of materials expected in operational environment and modify database to include acoustic signatures for those materials

This task focused on providing the client (military end-users) of the PASS with an initial custom acoustic signature database, using a PNNL-developed technology platform that provides the capability to automatically characterize and measure the acoustic properties of fluids as a function of temperature. This technology platform is known as the Velocity Characterization System (VCS). This task included all activities associated with generating an acoustic signature database consisting of acoustic velocitytemperature profiles for a specific list of chemicals associated with the needs of military first responders, inspectors, rapid deployment forces, law-enforcement and Naval boarding parties conducting on-board inspections using PASS. This database was designed for use with the Phase 1-modified PASS for noninvasive, nondestructive identification and inspection of liquids in sealed containers. Work included modification of the data acquisition platform to comply with safety procedures and protocols for measurement of various chemicals and off-gassing of volatiles and other components during the measurement process. This effort included repeatability of measured values and database validation activities in order to provide high-quality acoustic velocity-temperature profiles for specific fluids (commodities) not currently in the PASS database. A liquid characterization standard operating procedure (SOP) was also developed as part of this effort.

\section{PNNL Subtask 2.2 (TS 3.2). Perform operational testing to ensure all issues have been adequately addressed}

This task focused on validating the usefulness, effectiveness and reliability of the custom-made acoustic signature database for the PASS units fabricated, tested and deployed on this project for military use. After generating the new database for these units, a suite of laboratory validation tests were performed and these activities included acquisition, evaluation and documentation of the validation and operational performance of the PASS device using the newly developed database. A validation test procedure was generated and validation test results were recorded, analyzed and are presented here in this technical letter report (TLR). 


\subsubsection{PNNL Task 3 (TS 4.0). Optest/Performance Evaluation and Support (PNNL)}

(TS 4.1, 4.2, 4.3) This task included participation of all project partners at various levels of effort with the objective of demonstrating the use and applicability of the PASS to ONR and NAVCENTCOM personnel, and to train these personnel in the use of the PASS for non-invasive inspection and/or identification of liquid-filled containers and solid-form commodities. This task focused on conducting a performance demonstration, performing a basic operational evaluation of enhancements to the technology's functions and capabilities, and a comparison with observations made during the previous performance evaluation in Bahrain (May 2006). Additionally, military technology evaluation personnel from the ONR P38 unit were recruited as participants in the final operational testing and evaluation exercise in Phase 1. 


\subsection{PASS Database Generation System: The Velocity Characterization System}

This work is focused on providing military end-users of the PASS with a custom-made acoustic signature database, using a PNNL-developed technology platform that provides the capability to automatically characterize and measure the acoustic properties of fluids as a function of temperature. This technology platform is known as the VCS, and was employed on this project for the intended purpose of database generation for continued testing and evaluation of the PASS platform by military personnel.

This system was used to generate an acoustic signature database consisting of acoustic velocitytemperature profiles for a specific list of chemicals (22 specific liquids are described later in this document) associated with the needs of military first responders, inspectors, rapid deployment forces, and Naval boarding parties conducting ship-board inspections of liquid-filled containers. This database was designed for use on the commercially available PASS for non-invasive, nondestructive identification and inspection of liquids in sealed containers. This work focused on readying the platform for characterization of a wide variety of liquid chemicals and entailed configuring the VCS platform for effective characterization of alcohols, fuels, chemicals, caustic and hazardous liquids to comply with U.S. Department of Energy and PNNL safety requirements and regulations in the conduct of this work.

The PASS measures the acoustic time-of-flight of a sound pulse that travels through a bulk-solid material or liquid-filled container and computes the acoustic velocity of the item being examined. This computed value is compared with pre-measured values of acoustic velocity in a database that is presently limited in its scope. The database presently lists acoustic velocity values for these items, some as a function of temperature. When acoustic velocity information is measured, it is necessary to know the temperature of the material under test (or the ambient temperature when making the measurement) in order to properly compensate for temperature-induced changes in the acoustic velocity. By developing a temperature correlation algorithm, invoking a field-container temperature measurement capability and enhancing the database with velocity data as a function of temperature (over a large temperature range), these ambiguities can be accommodated. The VCS sensors actively transmit and/or receive acoustic wave energy. The VCS unit operates in the pitch-catch or "through-transmission" mode. Pulse-echo refers to the use of a single transducer for both transmission of ultrasound and reception of the return signal response (echo). Pitch-catch refers to a configuration where one transducer is used as a transmitting source and the other is used for reception of sound. As the sound field propagates through the liquid, the acoustic wave is modified by the density, compressibility, viscosity and other material properties of the liquid medium. The received ultrasonic signals carry information about the physical parameters of the liquid.

\subsection{Principles of Operation for Liquid Acoustic Velocity Measurements}

This section describes the principles of operation of the PASS/Portable Acoustic Contraband Detector (PACD) and fundamental VCS technology as it currently exists and covers technical background information pertinent to a review and analysis of the data acquired on this project. 
Ultrasonic sensors are used in a large variety of ways. New fields of ultrasonic sensor and ultrasonic sensor system applications include process monitoring and control, automotive examination techniques, chemical analysis, medical imaging, material property measurements, etc. These applications have enjoyed a rapid increase of interest in recent years. The development of new ultrasonic sensors and technology platforms was and is essentially accelerated by the progress in electronics, by new piezoelectric materials, by exploitation of new technologies and by the need for new or more accurate analysis methods in the industrial sector. The PACD technology is one example of an integrated ultrasonic sensor platform.

The PACD platform uses ultrasonic sensors or "transducers," which transform an electrical signal into an ultrasonic wave and vice versa. They actively transmit and receive acoustic wave energy. Piezoelectricity is the most commonly used physical effect. The PACD operates in a pulse-echo mode where the same transducer is used for both ultrasonic transmission and reception of energy. On its path from the transducer, into the container or material and back to the transducer, the acoustic wave is modified by the properties that are under investigation. The ultrasonic signal carries the information about the parameters to be measured. The PACD sensor platform not only detects the ultrasonic energy, but also extracts and evaluates the information carried by the ultrasonic signal in an efficient manner with high accuracy and resolution, by dedicated electronic hardware. Software algorithms are employed in order to analyze the ultrasonic propagation, and compute information from the interaction between the ultrasonic wave and physical or chemical variables of interest.

The PACD system operates at two different frequencies, a low-frequency of $200 \mathrm{kHz}$ for increased penetration (i.e., larger containers and more attenuative materials), and a higher frequency of $1 \mathrm{MHz}$ for increased resolution (i.e., smaller containers and less attenuative materials). The applications provided for in this project have focused on the 1-MHz frequency of use for the PACD platform. The use of ultrasonic energy enables the PACD to be non-invasive and non-intrusive as the acoustic wave is capable of penetrating through bulk-solid commodities and through the walls of liquid-filled containers. The PACD is based on the use of compressional (or longitudinal) wave energy and generates the ultrasonic energy by utilizing piezoelectric materials. These two specific frequencies were chosen for providing optimal coverage and penetration while maintaining high sensitivity and resolution over a wide range of commodities, fluids and container sizes/geometries.

Acoustic velocity and attenuation are very valuable tools for the study of the physical properties of solids and liquids. These two very important parameters are defined by the solution

$$
A=A_{0} e^{-\alpha z} \cos (k z-\omega t)
$$

for an ultrasonic wave propagating in the z-direction with a propagation constant

$$
\mathrm{k}=2 \pi / \lambda=2 \pi \mathrm{f} / \mathrm{v}
$$

a radian frequency

$$
\omega=2 \pi f
$$

and an attenuation coefficient $\alpha$. 
In these definitions, $\lambda$ is the wavelength, $f$ is the frequency, and $v$ is the phase velocity. In this traveling wave, the measurable quantities of interest to our application generally are $v$ and $\alpha$. These two parameters are strongly dependent on the properties of the media the wave is traveling through, and both are the primary factors that determine the wave propagation. Molecular interactions, phase transitions, molecular rearrangements and other effects are responsible for the behavior of $v$ and $\alpha$. The phase velocity is a function of the appropriate elastic modulus $M$ of the mode being propagated; and the relationship is

$$
v=(M / \rho)^{1 / 2}
$$

where $\rho$ is the density. For fluids the modulus $M$ is the adiabatic bulk modulus B and the waves are longitudinal (which is the case for applications with the PACD). For solids, $M$ is an appropriate combination of the elastic moduli of the solid itself and is influenced by many physical phenomena.

In an unbound solid medium, the compressional (longitudinal) velocity of sound is given as

$$
v_{\mathrm{L}}^{2}=[\mathbf{K}+(4 / 3) \mathrm{G}] \rho^{-1}
$$

where $\mathbf{K}$ is the bulk modulus, $\mathrm{G}$ is the shear modulus, and $\rho$ is the density. For fluid systems, the behavior of ultrasonic energy is more complicated in comparison to other materials. In liquids, the velocity of sound is described by

$$
v_{\mathrm{L}}^{2}=(1 / \rho \beta)=(\mathrm{B} / \rho)
$$

where $\beta$ is the adiabatic compressibility of the fluid and $\mathrm{B}$ is the adiabatic bulk modulus. $\beta$, $\mathrm{B}$ and $\rho$ are substance-specific integral parameters. In electrolytes, for instance, $\beta$ changes very strongly with little variation of the ion concentration or the particular type of ions. Many fluid systems that are predominant in industry and various technical applications are multi-component systems such as suspensions, dispersions, emulsions, colloidal systems or aerosols. Their acoustic behavior cannot be described easily. Sound propagation in these fluids is characterized by the influence of different material parameters like density, viscosity, thermal conductivity, thermal capacity, thermal expansion of the different phases, and particle dimensions (radius or diameter) in the dispersion or suspension. These parameters can be temperature and pressure dependent, resulting in both positive and negative temperature coefficients of velocity. The acoustic velocity can be experimentally determined using a variety of methodologies and laboratory techniques; however, the PACD and VCS platforms are based on two rather simple equations at a specific measurement temperature. These units compute acoustic velocity from the equation shown here:

$$
\text { Velocity }=\text { Acoustic Path Length/((Time-of-Flight }) / 2)
$$

Consequently, the acoustic velocity is reduced to the measurement of time-of-flight of acoustic pulses that propagate within the boundary of the container or bulk-solid commodity. At present, the PACD measures the acoustic time-of-flight of a sound pulse that travels through a bulk-solid material or liquidfilled container and computes the acoustic velocity of the item being examined. This computed value is compared with pre-measured values of acoustic velocity in a database that is created by the VCS platform and correlated with temperature-velocity data profiles. The database presently lists acoustic velocity values for these items as a function of temperature. By using only one physical property measurement for 
discrimination and identification modalities, the unit may provide multiple results due to overlapping velocity values at a specific temperature with commodities or liquids inherently similar in nature.

When acoustic velocity information is extracted in the field, it is necessary to know the temperature of the material under test (or the ambient temperature when making the measurement) in order to properly compensate for temperature-induced changes in the acoustic velocity. By developing a temperature correlation algorithm, invoking a temperature measurement capability and enhancing the database with velocity data as a function of temperature (over a large temperature range), these ambiguities can be significantly reduced.

\subsection{Mechanical Design Features and Operation Principles of the VCS}

Specific operational requirements focus on the VCS platform being operated by properly trained PNNL staff. The device is highly automated, easy to use, and provides comprehensive acoustic characterization results in less than a 2-hour period for a single liquid sample. The design meets these requirements and includes a heater/cooler platform using Peltier ${ }^{\circledR}$ devices; a data acquisition electronics module; high-frequency transducer $(1 \mathrm{MHz})$; a system control module; a removable liquid containment module with retractable mixing device; and a laptop for data control, analysis and archival. Finally, specific portions of the system (where secondary containment is required) are placed within a berm for containment in the highly unlikely possibility of leaks during operation. Also, access to a suitably sized fume hood is required when characterizing hazardous fluids. The design includes consistently affixed ultrasonic transducers to the outer wall of the liquid containment module. The VCS is shown in Figure 4.1.

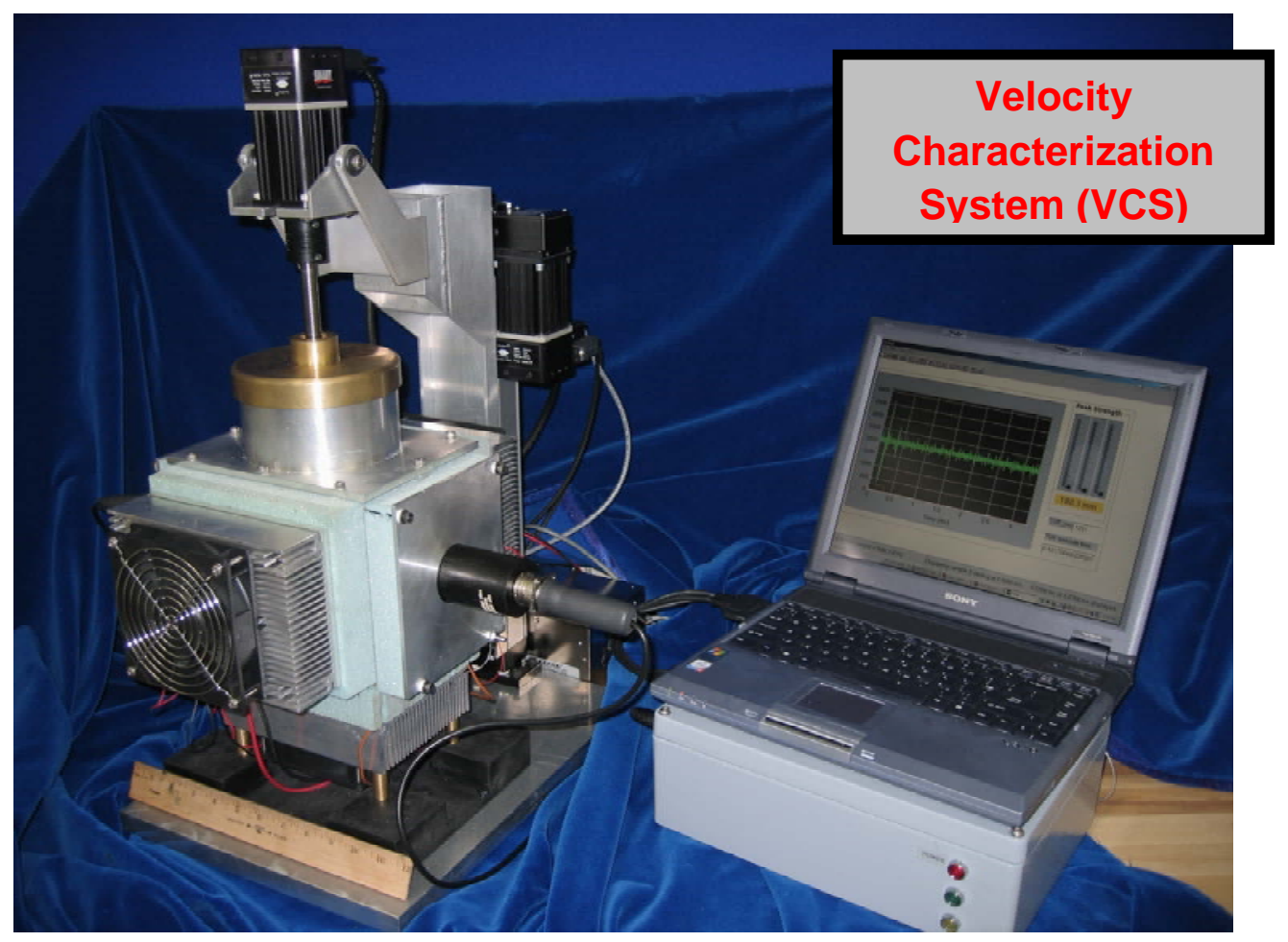

Figure 4.1. VCS System at PNNL Used for Database Generation for PASS 
The ultrasonic velocity data are temperature-dependent physical properties of the propagation medium. The VCS platform collects, and passes to the laptop platform, digitized waveforms of the ultrasonic return signal along with the present temperature reading. On the laptop, a PNNL-developed algorithm uses this information, along with the path length measurement input, to accurately calculate a temperature-corrected ultrasonic velocity value. The technical details of the calculations are transparent to the user. Prior to characterization, the user inputs the required information, which may include temperature range, temperature increment step size, container information, etc. The characterization results are presented graphically for clear interpretation by the user at the end of the characterization run. The results are merged with the user input to form a separate report file that may be transmitted electronically, printed out on paper or archived for later retrieval. These calculated values are automatically ported to a database listing for the specific liquid being characterized and a comprehensive file for this liquid is generated and ready for downloading at the end of the characterization process. The data are plotted and a 2nd order polynomial fit is applied to the data. The equation of fit is then entered into a database text file onboard the PASS for real-time temperature compensation of measured acoustic velocity in the field.

\subsection{Location, Safety and General Process of Database Generation Measurements Work}

The liquids were procured from various chemical supply companies or at commercial retail businesses and stored in pristine condition prior to measurement. All liquids were held in a proper storage facility with the appropriate physical security and safety equipment, protocols and procedures in place for receipt, handling, storage, maintenance and acoustic characterization and measurements. Proper disposal of the liquid samples was conducted in compliance with all Federal and Washington State environmental regulations for these substances. The work was conducted in a certified fume-hood with a suite of environmental monitoring and ambient air sampling sensors to monitor all levels of off-gassing during the measurement process. All facets of PNNL's environmental safety and health program were reviewed and applied as appropriate to this project, prior to, during and after the measurements were conducted. Safety walkthroughs were routinely conducted and all subsequent monitoring of effluents and off-gassing were substantially lower (in total concentration) than all established ceilings for the chemicals used on this project. All activities were performed at PNNL; a National Laboratory Complex operated by Battelle Memorial Institute for the U.S. Department of Energy and located in Richland, Washington. 


\subsection{Task 1 Results and Conclusions}

\subsection{Software Crashes}

To resolve occasional software crashes, Spearhead Innovations Inc., through a subcontract with the PNNL, teamed with their sister company responsible for manufacturing the device (International Engineering \& Manufacturing) and initiated the effort by compiling a list of situations during which PACD users experienced crashes. In addition to this, the SI/IE\&M team hired new technical staff that were unfamiliar with the PASS technology to independently evaluate the original design of the PASS software.

The PASS device makes use of the Hewlett-Packard hand-held's built-in Ethernet capabilities to connect the $\mathrm{PAAQ}^{\circledR}$ and the sensor. During initialization, the old version of the PASS software would periodically freeze while attempting to establish this Ethernet connection. To resolve this condition, SI/IE\&M changed the connection creation method to be asynchronous. This allowed the PASS software to continue to be responsive and provide connection status to the operator while the connection was being established. By making this connection creation asynchronous, it also allowed for a limitation to be established regarding how long the PASS software would wait on a response from the Pico board (communications board) before issuing a connection failure message to the operator. Also, the iPAQ's operating system includes a timer that causes the iPAQ ${ }^{\circledR}$ to shut down after one minute. To prevent the system from shutting down while an operator is inspecting containers, SI/IE\&M modified the system to reset the shutdown timer each time the actuator is pressed.

The SI/IE\&M team also changed the communication timeout period. It is possible for the Ethernet communication link between the sensor and the $\mathrm{iPAQ}^{\circledR}$ to fail as a result of a loose cable or an issue with the Pico board. In order to recover from this connection failure, a maximum timeout of 20 seconds was added while the software is in receiving mode. The software is in this receiving mode while an operator is actively making inspections. This communication timeout allows an error to be displayed to the operator informing them of the connection failure. Some connection issues related to the Pico board can be recovered from automatically while other Pico board issues may require the iPAQ ${ }^{\circledR}$ and/or sensor to be power cycled.

The SI/IE\&M team also added a power management awareness feature to the software. SI/IE\&M discovered that when the iPAQ ${ }^{\circledR}$ is idle, the iPAQ's power save mode puts the iPAQ ${ }^{\circledR}$ into a hibernation state. When the system wakes up from this hibernation state, it takes approximately ten seconds for the system to re-establish its Ethernet connection with the sensor. SI/IE\&M software engineers added a power management thread to detect this condition. This allowed for the provision of a "please wait" dialog message while the system is re-establishing connection with the sensor.

Finally, the SI/IE\&M team restructured the code that creates and manages the multiple threads within the software. The previous code had potential threading issues such as concurrent access to global variables and timing issues with the event handlers. These issues were identified as sources of potential failures in any one of the threads, such as the GUI thread. An unresponsive GUI could indicate failures in the GUI thread. By restructuring the code and changing the use of specific code operators the SI/IE\&M team are confident that the potential for threading issues has been minimized/eliminated. 


\subsection{Battery Power Indicator}

Adding a battery power indicator to the PASS software's GUI was complicated by the fact that the only time the $\mathrm{iPAQ}^{\circledR}$ receives battery voltage information is when the operator has the actuator button pressed during an inspection. Also complicating this task is the fact that, when the actuator button is pressed, a real-time graph is displayed that is not conducive to a power indicator icon. Because of this, the power indicator icon was added to the main PASS screen, which is not displayed when the PASS unit is actually taking measurements, but is again displayed when the measurement is complete. To allow dynamic battery power updates to the main screen, an asynchronous message handler was added. The main screen layout was changed to include an updatable icon representing the sensor's battery power. After the code was written to extract the voltage information, testing was performed to check the battery's loss of power.

The sensor uses a lithium ion battery with a non-linear power loss curve. To display an accurate representation of the battery's power, a non-linear power curve was mapped to a power scale of $0 \%$ to 100\%. $100 \%$ represents a fully charged battery and $0 \%$ represents a battery that can no longer issue enough current to run the transducer. Powering the transducer provides the greatest load on the battery. When developing the power scale for the indicator icon, the SI/IE\&M team took into account the discovery that in the original software, when the battery could no longer sustain 5 volts of output, the sensor's EPROM's would lose their firmware. To prevent this, a safety circuit was added to shut down the circuit boards if the power fell to 5 volts. While this prevented the loss of firmware, it contributed to the PASS software lock-ups because the software could no longer communicate with the sensor.

SI/IE\&M development engineers created a new dialog box notifying the operator when the battery can no longer support the sensor. This solution was found to aid in reducing software lockups. Figures 5.1 and 5.2 show the new battery power indicator icon reflecting $100 \%$ and $0 \%$ power remaining, respectively.

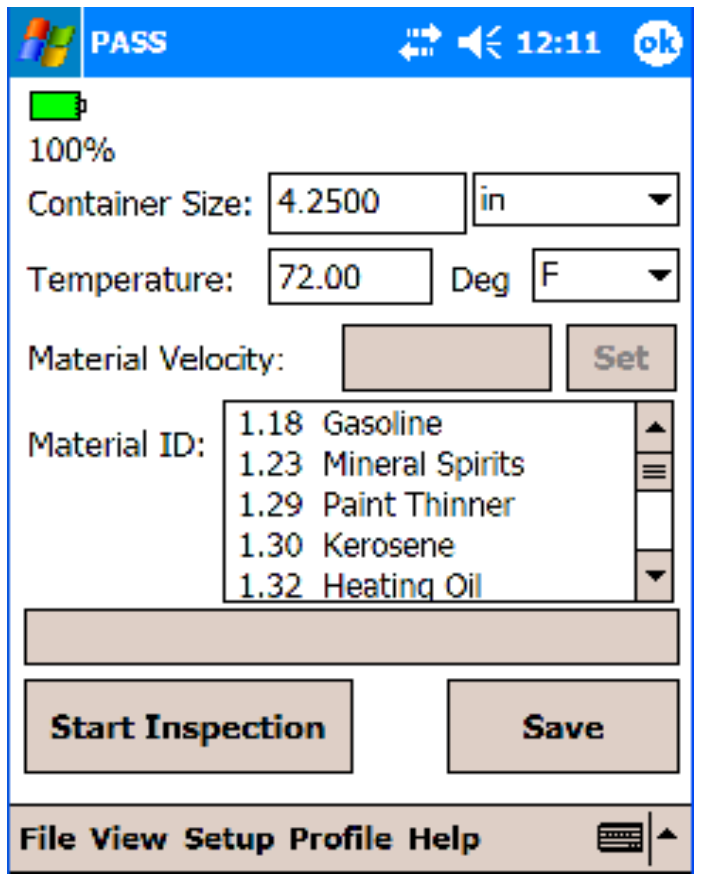

Figure 5.1. Battery is at Full Power 


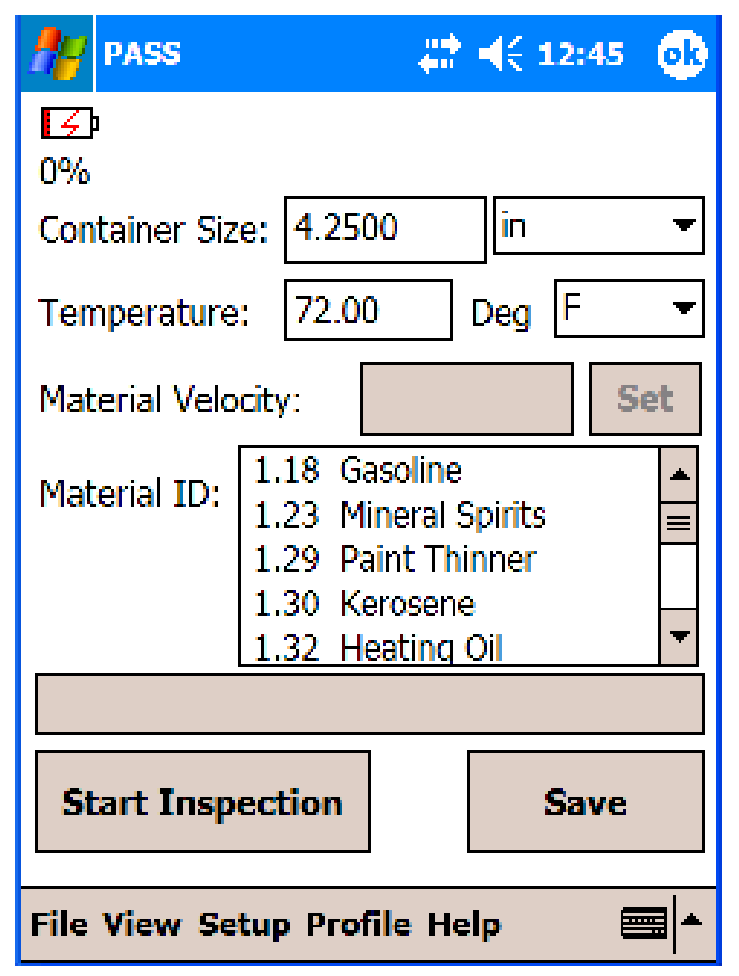

Figure 5.2. Battery No Longer Supports System Operation

\subsection{Sunlight Mitigation}

In order to improve visibility of the PDA screen in bright conditions, the SI/IE\&M team sought to address the problem on a variety of fronts, including:

1. removal of reflections from the PDA screen,

2. brighten the screen image,

3. increase the contrast of the screen image, and

4. increase backlighting.

\subsubsection{Testing in Bright Sunlight}

Upon testing the PDA in bright sunlight conditions, the PDA was easier to read when the sunlight was directed onto the PDA screen (from behind, over user's shoulder onto screen). With the sunlight directed into the user's face, reflecting onto the screen, the PDA was hard to read.

\subsubsection{Approach}

Sample filters were tested to reduce reflections and increase contrast.

Transflective and anti-reflective films reduced the reflections but lowered the brightness of the screen and reduced screen sharpness. These filters reduced reflections and glare but gave a $<10$ percent better readability to the PDA screen. Opaque hoods also reduced reflection but were cumbersome. 
Fresnel lenses and mounted lighting (directed at the screen) were employed and evaluated to increase brightness and contrast. The resultant amount of increase in brightness and contrast was minimal.

Glass filters of the above types seemed to improve readability better than the film; however, they were not suitable for the PDA touch screen.

SI/IE\&M shipped an iPAQ ${ }^{\circledR}$ to a subcontractor to have a film bonded to the PDA. The company claims that the process provides

1. higher contrast,

2. improved overall sunlight readability of the LCD,

3. stronger display durability/ruggedization,

4. better thermal dissipation, and

5. reduction of reflections

SI/IE\&M received the iPAQ ${ }^{\circledR}$ back from the company with the bonded screen enhancement and again tested it against iPAQs with and without screen filters. The treated $\mathrm{PAQ}^{\circledR}$ was noticeably brighter with reduced reflection and glare, making the screen's readability in direct sunlight 15-20 percent better than non-treated PDAs. The bonded screen filter seems to be the best sunlight mitigation enhancement because it increased brightness, reduced reflections, and reduced glare while maintaining sharp contrast.

The SI/IE\&M development team concluded that in order to achieve still greater readability in bright sunlight, more backlight would be necessary, and thus a different PDA would be required. Use of a different PDA would require additional software changes that to date have not been scoped into the current effort for PDA improvement planning; however, SI/IE\&M engineers can certainly evaluate this potential option should the client wish to pursue this path. 


\subsection{Task 2 Results and Conclusions}

\subsection{Acoustic Characterization of Liquids}

PNNL initiated the effort by holding discussions and routing requests for information to all participating organizations for vetting and eventual determination of a final list of liquids for characterization and inclusion into the Phase 1 database. Initial discussions resulted in the formulation of five general categories (classifications) of liquids to be considered for characterization, where multiple liquids were identified in each category. These general categories included:

Food Products, Cooking Oils, Herb-Based Oils, etc.

- Olive Oil (pure) or Corn Oil

- Date Vinegar

- Balsamic Vinegar

- Honey

- Frankincense

- Myrrh

- Water

Multi-Use Common Chemicals (industrial chemicals, solvents, etc.)

- Alcohol (isopropyl 70\% or $90 \%$ )

- Alcohol (ethanol)

- Alcohol (methanol)

- Chloroform

- Ethyl Ether

- Hydrochloric Acid (39.1\% in solution)

- Methylethylketone (MEK, i.e., solvent)

- n-Hexane

- Isosafrol (cis- and trans-)

- Phenylacetic Acid

- Ergometrine

- Acetyl Chloride

- Pyridine

- Toluene

- Xylene

Common Petroleum Liquids (refined and unrefined)

- Diesel \#1 and Diesel \#2

- Marine Diesel

- Gasoline (87 and 92 octane)

- Jet Fuel (Type A)

- Kerosene (low-grade camping 1-K) 
- Motor Oil (refined - 10W30 or 10W40 or SAE30)

- Crude Oil (unrefined - heavy crude, 8-12 API)

\section{Other Liquids}

- Hydrogen Peroxide (3\% to 35\% in solution)

- Glycols ethylene orethanol, i.e., antifreeze)

\section{Illicit Liquid Drugs}

- Liquid Methamphetamine (concentration?)

- Liquid Heroin (concentration?)

Multiple iterations (team discussions) were eventually successful in identifying a final list of liquids based upon criteria such as the level of difficulty in acquiring specific liquids (time, cost, level of effort), and measurement system requirements and ramifications. The final list of liquids chosen for acoustic characterization and inclusion in the PACD database can be found in Appendix A.

PNNL initiated early analysis of each liquid on the list, including an environment, safety and health assessment of each liquid based on the individual liquid properties, rheology and data found in the Material Safety Data Sheet (MSDS) documentation for each liquid. PNNL then embarked on obtaining 2- to 2.5-gallon volumes of each specific liquid and began to baseline the operation and performance of the VCS platform with de-ionized water as the liquid reference liquid. Operational and measurement safety procedures and processes were generated and approved, all MSDS documentation was obtained, and all peripheral equipment such as pumps and hoses for VCS evacuation of liquids were also acquired. The team began generating a procedure for handling the propeller and evacuation of liquids and disposal of waste that eventually became the basis for the VCS SOP. All primary and sub-components of the VCS were labeled and separated for movement into a fume hood. Digital photographs were taken and the system was brought up for full operation. Multiple runs on de-ionized water were performed between $40^{\circ} \mathrm{F}$ and $120^{\circ} \mathrm{F}$ in $10^{\circ} \mathrm{F}$ increments (both temperature directions, from low-to-high and high-to-low). The VCS system was validated by comparing (baselining) the results to that of water values provided from the literature. In the field of ultrasonics, de-ionized water is the most prevalent liquid characterized using acoustic property measurements, and thus water is an ideal liquid metric for validation of the system performance. Initial runs on samples of fuels and alcohols also provided our team with a better understanding of the impact of evaporation during the measurement process, the measurement variation (resultant polynomial fits) between runs on the same fluid, and the impact of chemical interactions between various liquids and the aluminum container.

\subsection{Industrial Hygiene Monitoring Results of VCS Liquids}

Evaporation and outgassing of the liquid samples during VCS analysis were reduced to insignificant levels by employing various seal materials that were placed inside the mixing propeller housing to seat the housing on top of the VCS containment. This essentially eliminated any evaporation effects and significantly reduced outgassing during operation inside the fume hood. Table 6.1 below lists the dates and organic solvents for which air sampling was conducted using passive organic vapor monitors (POVM) to determine operator inhalation exposure to the solvents while PNNL staff members performed work to determine the acoustic characterization of each of the solvents. In addition to attaching POVMs to the lapel of VCS operators to determine personal exposure levels, POVMs were also placed outside the 
fume hood to determine effectiveness of engineering controls in minimizing fugitive vapors. A POVM was placed $\sim 3$ feet from the VCS apparatus on left side of the fume hood front, 4 feet above the floor and one was placed $\sim 5$ feet from the VCS apparatus on the lab bench in front of the hood, 5 feet above the floor.

The work area that was sampled was located in 2400 Stevens in lab space 1441 in fume hood \#1, a 4-foot LabConco ${ }^{\circledR}$ Protector Laboratory Hood with a capture (face) velocity of 120 linear feet per minute. The capture velocity was certified by Facility \& Operations Ventilation and Balance in April 2007. Approximately 2.5 liters of each solvent was placed in a 2.5-liter-capacity ultrasonic analyzer, velocity characterization system, to measure the acoustic velocity for each solvent as a function of temperature. The outside diameter of the aluminum reactor shell was fitted with thermoelectric modules. When the thermoelectric modules were energized, the solvent contained in the reactor was heated to temperatures of up to $135^{\circ} \mathrm{F}$. Each solvent had its' acoustic velocity measured twice at various temperature set/hold points in a one-day period with only a single solvent being tested each day. With elevated temperatures, generation of vapors via evaporation was expected to increase. Testing of the solvents took place inside the fume hood in lab space 1441 to mitigate fire and exposure hazards. The work with these chemicals was authorized and controlled under 2400STV-1226-1441-CPP-8468, Rev: 2, Ultrasonic Characterization of Liquids. Exposure limits ${ }^{(a)}$ were applied as described below and an 8-hr TWA (time weighted average) was also applied in this analysis of results.

Engineering Controls during activity: The slip-fitting lid for the 2.5-liter capacity ultrasonic analyzer and the local exhaust (laboratory fume hood).

Administrative Controls during activity: all chemicals labeled; all chemicals included in the PNNL Chemical Management System; amount of chemicals within inventory limits; MSDS available and reviewed for all chemicals; and this exposure monitoring; see 2400STV-1226-1441-CPP-8468, Rev: 2, Ultrasonic Characterization of Liquids.

Personal Protective Equipment worn during activity: Safety glasses with side shields and chemical resistant gloves specified in 2400STV-1226-1441-CPP-8468, Rev: 2, Ultrasonic Characterization of Liquids.

Actions: No additional actions were required during the conduct of this as the project team was diligent with regard to the conduct of all safety operations and the VCS platform operated well within the design and operational specifications provided prior to the conduct of work.

(a) Exposure limits - the exposure limits listed are either from federal OSHA (PEL, STEL, AL, or Ceiling), Washington State OSHA (PEL, STEL, AL, or Ceiling), or the American Conference of Governmental Industrial Hygienists (TLV, STEL, or Ceiling) whichever is the lowest and affords the greatest level of protection to the worker. The personal sampling results indicate that all personal exposures were less than the applicable exposure limits for all solvents sampled. The area sampling results from POVMs placed outside the fume hood also document that the engineering controls were very effective in minimizing fugitive vapors as none of the solvents were detected by any of the POVMs placed outside the fume hood. 
Table 6.1. Industrial Hygiene Monitoring Results for Various Organic Solvents Characterized by VCS

\begin{tabular}{||c|c|c|c|c|c|c|}
\hline \hline Date & Solvent & mg/Sample & Parts per Million & Calculated & 8-hr. TWA $^{\mathbf{1}}$ & Ceiling $^{\mathbf{2}}$ /STEL $^{\mathbf{3}}$ \\
\hline 4-23-07 & Chloroform & 0.020 & $0.53 \mathrm{ppm}$ & $0.50 \mathrm{ppm}$ & $10 \mathrm{ppm}$ & $50 \mathrm{ppm}$ ceiling \\
\hline $4-24-07$ & n-Hexane & None Detected & $<0.39 \mathrm{ppm}$ & $<0.26 \mathrm{ppm}$ & $50 \mathrm{ppm}$ & None \\
\hline $4-25-07$ & Xylene & None Detected & $<0.36 \mathrm{ppm}$ & $<0.02 \mathrm{ppm}$ & $100 \mathrm{ppm}$ & $150 \mathrm{ppm} \mathrm{STEL}$ \\
\hline $4-26-07$ & $\begin{array}{c}\text { Methylene } \\
\text { Chloride }\end{array}$ & 0.073 & $1.1 \mathrm{ppm}$ & $0.32 \mathrm{ppm}$ & $25 \mathrm{ppm}$ & $\begin{array}{c}125 \mathrm{ppm} \mathrm{STEL} \\
\left(12.5 \mathrm{ppm} \mathrm{AL}^{4}\right)\end{array}$ \\
\hline $4-27-07$ & Benzene & None Detected & $<0.22 \mathrm{ppm}$ & $<0.09 \mathrm{ppm}$ & $0.5 \mathrm{ppm}$ & $\begin{array}{c}2.5 \mathrm{ppm} \mathrm{STEL} \\
\left(0.5 \mathrm{ppm} \mathrm{AL}^{4}\right)\end{array}$ \\
\hline
\end{tabular}

1. Time-Weighted Average (TWA) - This exposure limit is based on acceptable contaminant concentrations for a normal, 8-hour workday and a 40-hour workweek. A TWA is an exposure limit to which nearly all workers may have exposure to day after day, for a 40-hour work week, without experiencing any adverse health effects.

2. Short-Term Exposure Limit (STEL) - This is a 15-minute TWA exposure that should not be exceeded at any time during a workday. Exposures above the TWA up to the STEL should not be longer than 15 minutes and should not occur more than four times per day. Additionally, there should be at least 60 minutes between successive exposures in this range.

3. Ceiling (CEIL, C) - This refers to concentrations that must not be exceeded during any part of the working exposure. As such, ceiling TLVs (total level of volatiles) take precedent over all TWAs and STELs.

4. Action level (AL) - This refers to employee exposure, without regard to the use of respirators, to an airborne concentration of one half of the OSHA permissible exposure level (PEL) averaged over an 8-hour period (*-hr. TWA). In most single-substance air contaminant standards such as those for methylene chloride and benzene issued by OSHA, OSHA has set an action level equal to half the PEL. The action level triggers duties of monitoring, medical surveillance, and training, and assures that workers who are not exposed at or above the PEL but who may nevertheless be exposed to levels that present a risk to their health receive a degree of protection. The action level thus helps to reduce residual risk that may remain at the PEL.

Multiple characterization runs on each liquid were conducted using fresh batch samples, as acoustic property results from VCS indicated that the heating process affected the properties of the liquid by contributing to the loss of volatiles and/or other unknown constituents in the liquids that changed the properties of the liquid over time as the samples were heated and measured. Thus, multiple runs were indeed conducted, but each run was initiated with a fresh sample of liquid. This process resulted in very consistent results from run-to-run using the VCS. As an example, Table 6.2 shows some basic statistical correlation data between multiple runs of liquids used to baseline and evaluate the VCS precision (measurement consistency).

Table 6.2. Results from Evaluation of VCS Precision (measurement consistency) for Various Liquids. Maximum deviations for worst-case for each liquid shown.

\begin{tabular}{||l|c|c|c|c|c||}
\hline \multicolumn{1}{||c|}{ Liquid } & $\begin{array}{c}\text { Total } \\
\text { Number of } \\
\text { VCS Trials }\end{array}$ & $\begin{array}{c}\text { Minimum Number } \\
\text { of Measurement } \\
\text { Points in each Trial }\end{array}$ & $\begin{array}{c}\text { Maximum } \\
\text { Standard } \\
\text { Deviation } \\
\text { (km/sec) }\end{array}$ & $\begin{array}{c}\text { Temperature } \\
\text { Maximum } \\
\text { Coefficient of } \\
\text { Variation }\end{array}$ & $\begin{array}{c}\text { where Maximum } \\
\text { Deviation } \\
\text { Occurred }\end{array}$ \\
\hline Water & 8 & 10 & 0.00104 & 0.00075 & $\sim 40^{\circ} \mathrm{F}$ \\
\hline Olive Oil & 6 & 10 & 0.00140 & 0.00093 & $\sim 40^{\circ} \mathrm{F}$ \\
\hline SAE 30 Motor Oil & 4 & At least 8 & 0.00238 & 0.00163 & $\sim 70^{\circ} \mathrm{F}$ \\
\hline Jet Fuel (A) & 2 & 9 & 0.00111 & 0.00080 & $\sim 40^{\circ} \mathrm{F}$ \\
\hline
\end{tabular}


Olive oil is a representative example of the repeatability observed for velocity-temperature profiles where data were acquired for multiple runs on a liquid with a fresh sample volume for each trial, and where the data were acquired by first ramping up in temperature and then down in temperature. This activity was also conducted using the same liquid sample (by not changing out the liquid volume between runs). Results indicated that some liquids (fuels, for example) were inherently modified by the temperature ramping in the VCS where specific components of the liquids may have evaporated or otherwise been lost to thermal ramping that changed the resultant velocity profiles (shifting the 2nd run values). Thus, all liquids were characterized multiple times, using fresh liquid samples each time a trial run was initiated. Regardless of the commercial brand of olive oil, these data were extremely repeatable. The plot in Figure 6.1 illustrates this consistent behavior.

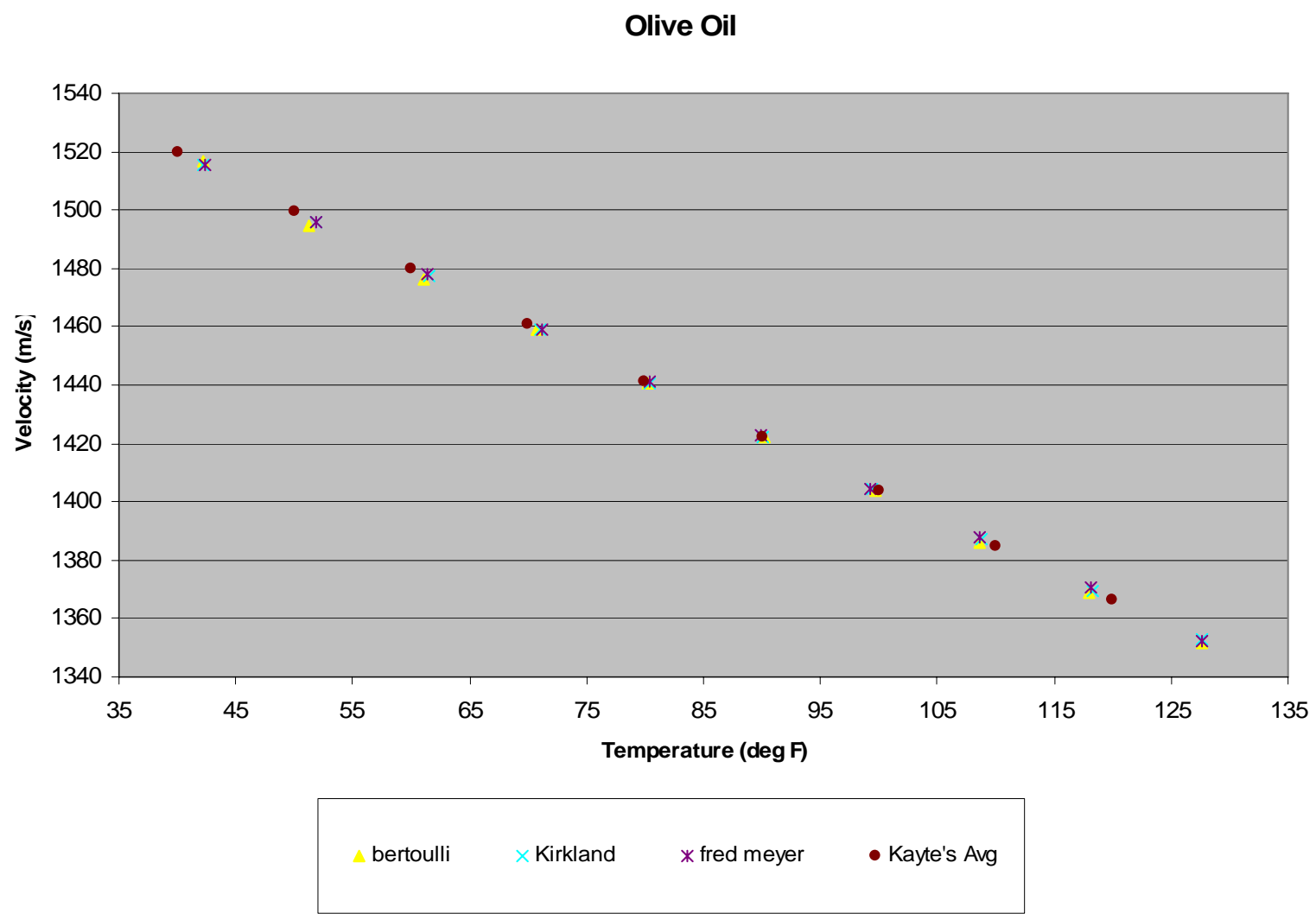

Figure 6.1. Multiple VCS Trial Runs on Olive Oil

With regard to VCS accuracy, de-ionized water was used as the baseline liquid and compared with a variety of well-established data in the literature that are used as standard acoustic property true-state values in research. One such reference from the American Institute of Physics (AIP) (Del Grosso and Mader 1972) provides laboratory reference data of sound speed versus temperature in pure water that was reviewed and employed in this analysis for comparison of VCS accuracy. The plot in Figure 6.2 shows the published data (over the same temperature regime) plotted against a composite average of all VCS data taken for water. Table 6.3 provides the results (basic statistical correlation) from an evaluation of the accuracy of the VCS using water as the baseline liquid. Our VCS data are well within a $0.5 \%$ error 
margin over the entire temperature range. It should be noted that many variables contribute to measurement variations using ultrasonic energy, as this modality is typically viewed as a "macroscopic" physical property measurement approach and should not be compared with highly precise methods used in analytical chemistry for instance. Such measurement variables (that always present themselves across published data in the literature) include:

- Transducer variability (manufacturing variance, near-field and far-field transition zones, directionality/sound field dimensions, intensity, performance characteristics, bandwidth, operational and center frequency, etc.)

- Velocity dispersion (changes in acoustic velocity with frequency)

- Control of temperature and elimination of thermal gradients

- Transducer alignment

- Accurate measure of path length between transducers

- Signal processing methodology applied (algorithm dependability for correct detection of appropriate echoes and for consistent time-of-flight computation).

\section{Water}

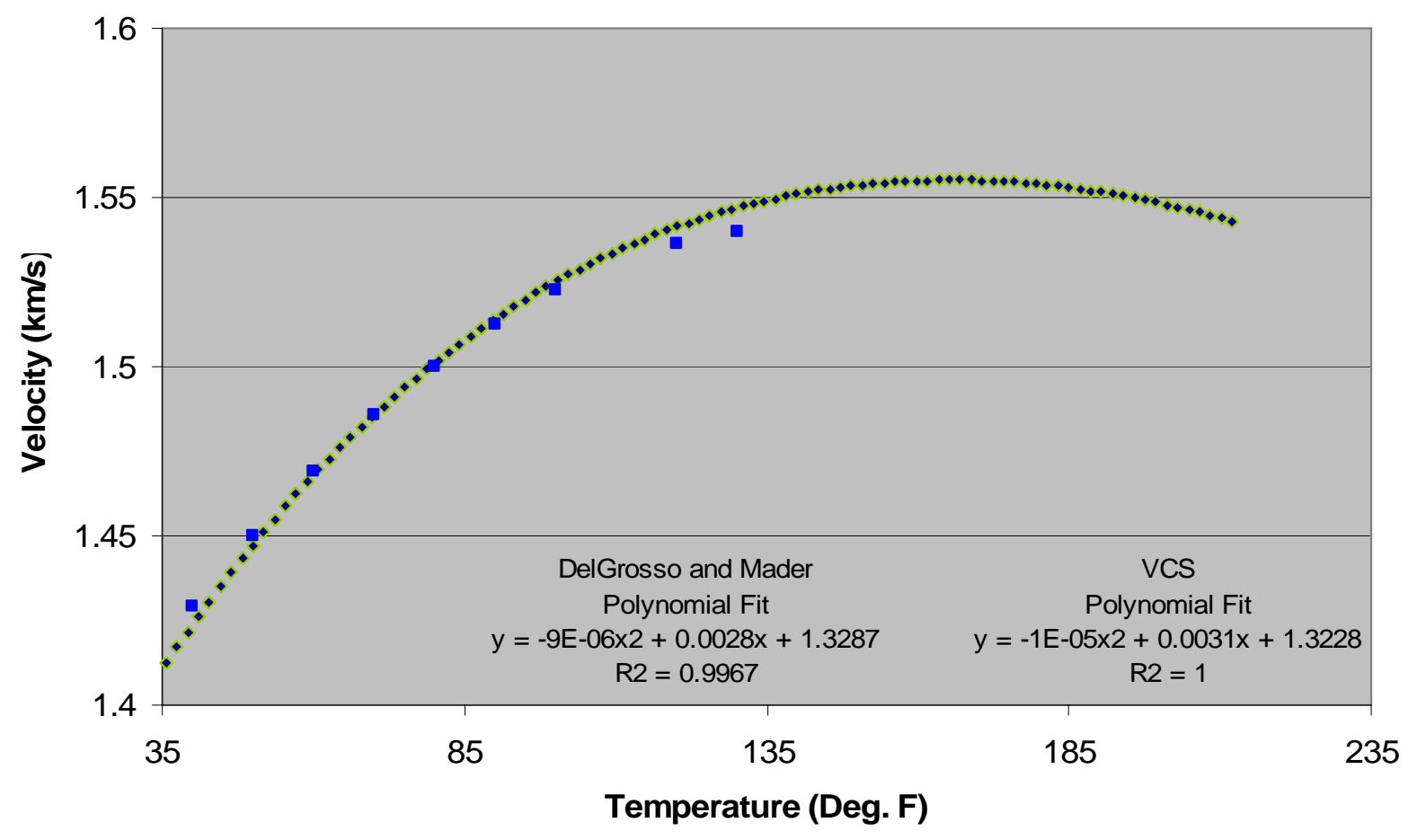

- DelGrosso and Mader,JASA, 1972 - VCS Data

Figure 6.2. Published Velocity-Temperature Profile for Pure Water Compared with VCS-Generated Data 
Table 6.3. Comparison of Results from Evaluation of VCS Accuracy for Water Based Upon a

Comparative Evaluation of Published Data in the Literature (Del Grosso and Mader 1972) and VCS Measured Data on Pure Water

\begin{tabular}{||c|c|c|c|c|c||}
\hline & Total & $\begin{array}{c}\text { Minimum } \\
\text { Number of } \\
\text { Measurement } \\
\text { Lumber of } \\
\text { Loints in Each } \\
\text { Trial }\end{array}$ & $\begin{array}{c}\text { Maximum } \\
\text { Standard } \\
\text { Deviation } \\
(\mathbf{k m} / \mathbf{s e c})\end{array}$ & $\begin{array}{c}\text { Maximum } \\
\text { Coefficient of } \\
\text { Variation }\end{array}$ & $\begin{array}{c}\text { Temperature } \\
\text { where Maximum } \\
\text { Deviation } \\
\text { Occurred }\end{array}$ \\
\hline Water (VCS) & 8 & 10 & 0.0048 & 0.0031 & $\sim 130^{\circ} \mathrm{F}$ \\
\hline Water (Literature) & $\mathrm{n} / \mathrm{a}$ & $\mathrm{n} / \mathrm{a}$ & Baseline & Baseline & Baseline \\
\hline
\end{tabular}

\section{Composite Profile for All Liquids}

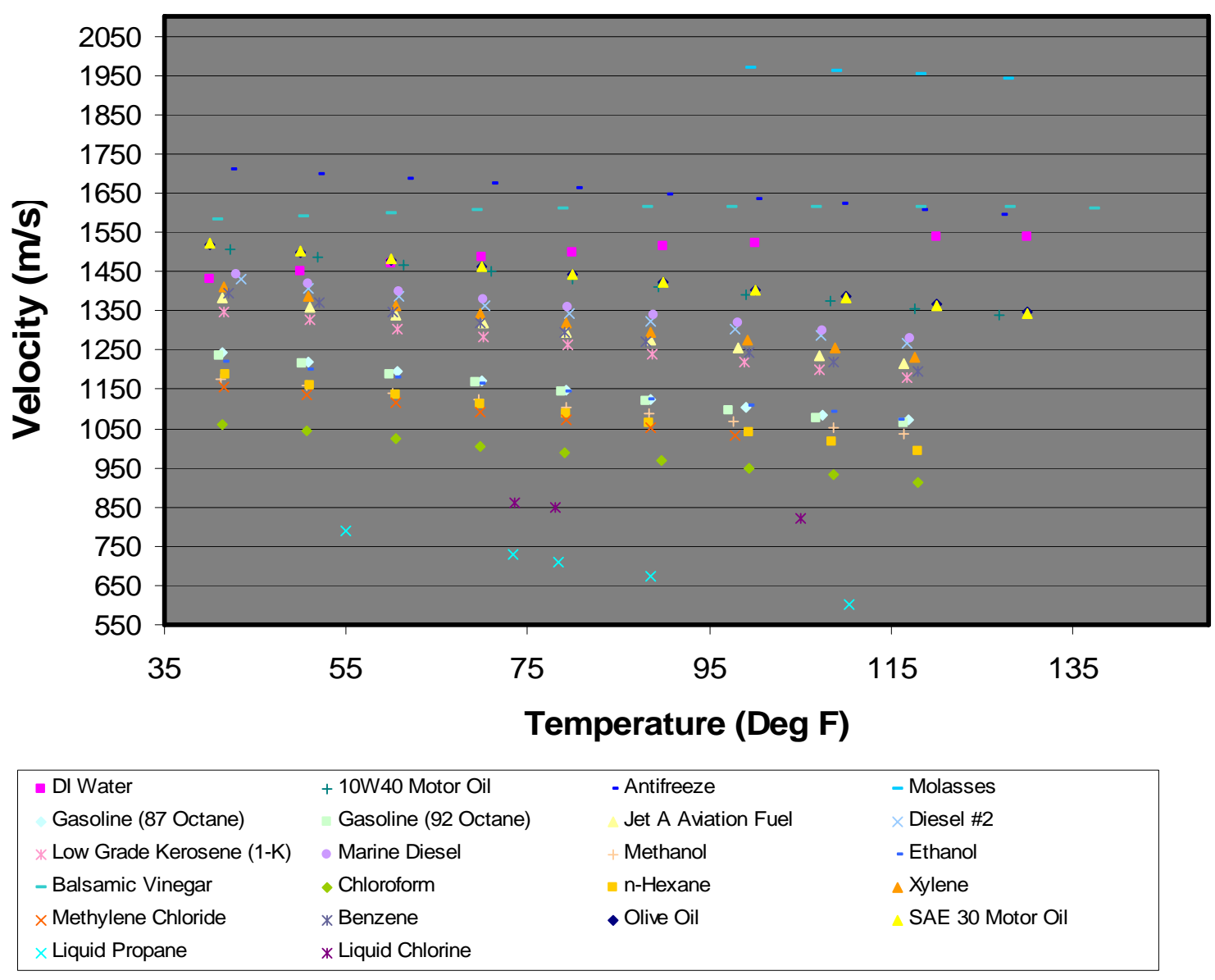

Figure 6.3. Composite Plot of all 22 Liquids Illustrating Acoustic Velocity as a Function of Temperature. Trendlines are not shown but the 2nd order polynomial fits are included in Appendix C. 
It should be noted that comparing accuracy between two sets of laboratory-acquired datasets is difficult to quantify with meaningful rigor, but the AIP data are used as a benchmark in the arena of ultrasonic physical property measurements. Thus, AIP data are being used here as a comparative metric to assess the performance of the VCS measurement process. Multiple characterization runs were conducted on various liquids, including water, olive oils (pure and extra light), and motor oils (SAE 30 and 10W40 from various vendors), and VCS performance characteristics and reliability/consistency were evaluated and validated. Technical confidence in the resultant characterization data is very high, and the VCS platform was routinely benchmarked using calibration runs on water to verify continued operational performance and measurement consistency and reliability throughout the measurement process.

During the measurement process (March 2007), a VCS power supply burned out. This power supply was used for powering the fans and heater/cooler (Peltier ${ }^{\circledR}$ ) devices, and essentially shut down the characterization operations until PNNL staff located an identical back-up power supply. Fortunately, PNNL had purchased a back-up unit in FY2004 when the VCS platform was originally fabricated, and this was immediately inserted into the VCS platform. The technical team only lost $1 / 2$ day in the process of electronics diagnostics and replacement of the unit. This was unanticipated and not scoped into this effort, but a procurement for a replacement to the original power supply was made and the unit was received in a matter of a few days. The system was up and operational, and continued to operate efficiently without further issues or delays throughout the life of the Phase 1 database effort.

PNNL's work continued through the spring of 2007 completing the acoustic velocity profiles for all Phase 1 liquids specified for completion in the Statement of Work, with the exception of Alaskan slope or Mexican (Mayan) crude oil, which is not-representative of crude oil from the Arabian Gulf. Crude oils vary considerably (with regard to chemistry and rheology) as a function of geographic location, time of year of extraction from the earth, and the type of crude oil (sour versus sweet crudes). The Alaskan Slope and Mexican Peninsula crude oil samples available to PNNL were sour crude oils (considered "heavy" crude in the oil industry) and contained significantly higher sulfur, heavy metals and asphaltene content than the lighter "sweet" crudes of the Persian Gulf. These crude oil samples are very viscous and quite difficult to propagate 1-MHz acoustic energy across. In addition, they have considerably different densities and viscosities than the types of crude oils encountered in the Persian Gulf. PNNL has much experience in acquisition of crude oil samples for materials property measurements on other programs, and has found it very challenging and time-consuming to acquire crude oil samples from domestic oil entities (Chevron, Conoco-Phillips, etc.), and even more difficult from Mexico. Acquisition of crude oil samples from the Persian Gulf would require a level of effort not scoped in Phase 1, and would also require the assistance of the military or other U.S. Government intermediary for logistics, identification and shipping/transportation of light crude oil from the Middle East. For these reasons, crude oil was not characterized during Phase 1, but tabled for discussion and potential characterization in Phase 2.

PNNL exceeded the number of liquids required to meet this deliverable and completed full acoustic characterizations of 22 liquids. These liquids included: de-ionized water, 87 octane gasoline, 92 octane gasoline, low-grade camping fuel kerosene (1-K), balsamic vinegar, methylene chloride, liquid propane, liquid chlorine, benzene, chloroform, marine diesel, 10W40 motor oil, antifreeze, jet-A aviation fuel, methanol, n-Hexane, olive oil, molasses, diesel \#2, ethanol, xylene and SAE30 motor oil. The complete list of fully characterized liquids added to the PACD database for Phase 1 can be found in Appendix A. A composite representation of all liquid profiles of acoustic velocity versus temperature is illustrated in Figure 6.3. The range spanning the various acoustic velocities for the 22 liquids is quite broad, where liquid propane (compressed) exhibits the slowest velocities over a range of $0.6 \mathrm{~km} / \mathrm{sec}$ to $0.79 \mathrm{~km} / \mathrm{sec}$ and 
conversely where molasses exhibits the fastest velocities over a range from $1.94 \mathrm{~km} / \mathrm{sec}$ to $1.97 \mathrm{~km} / \mathrm{sec}$. Each individual liquid velocity-temperature profile is provided in Appendix B and the corresponding 2nd order polynomial fits are provided in Appendix C.

After the PACD database was completed, PNNL staff members generated a new in-lab validation test procedure using a PNNL-owned model-1 PASS device on a subset of liquids over low, medium and high temperatures in both high density poly ethylene (HDPE), aluminum and stainless steel containers. The validation results are provided in Appendix D, where individual plots illustrate the measured data points superimposed over the VCS-generated velocity-temperature profile. A subset of seven liquids were used for this portion of the study, and they include, olive oil, antifreeze, gasoline (87 octane), diesel \#2, lowgrade camping fuel kerosene (1-K), balsamic vinegar and liquid propane (compressed). This evaluation included data on both curved containers and flat containers but focused on smaller sample volumes of liquid where the containers were $12 \mathrm{in}$. in diameter or less for the validation measurements. These data are essentially worst-case data because we have a good understanding of the effects and impacts of wall thickness on the resultant PASS velocities. These data have established the lower bound for measurement variation from the VCS-generated profiles. The validation procedures are detailed in a separate document and have been included in the Phase 1 deliverables package along with this TLR.

The data acquired during the in-lab validation effort showed that all measured data were within 2.5\% of the database values as a function of temperature, and many fell within a $1 \%$ margin. Smaller containers were used for this study to reduce costs associated with acquisition, storage, use and disposal of large volumes of liquids (i.e., 55-gallon drums). As discussed previously, as the path length decreases, the differences between PASS-measured values and database values will diverge. Differences in waveform shape will contribute to this type of difference between PASS-measured values and database values as well, particularly in smaller containers where the signal detection algorithm breaks down. Variations in the operator-measured temperature and distance are much more significant sources of error than the margins discussed here.

From the data in Appendix D, it can be seen that the stainless steel container yielded consistently higher offset in results than HDPE. In the next section, the convergence of data toward the line with larger containers is validated and shown. 


\subsection{Discussion and Recommendations}

PNNL was originally tasked with providing 15 to 20 liquid constituents to the new PACD database for this effort. The new database now contains 22 liquids with complete and validated acoustic velocitytemperature profiles. The VCS-generated data are both accurate and precise, and provide the necessary information onboard the PACD platform for initial operational testing and evaluation (OT\&E) of liquid identification and classification in sealed, liquid-filled containers.

Of the 22 liquids characterized for this effort, only 2 liquids were physically measured by other means, and these liquids include liquid propane and liquid chlorine in pressurized bottles. These sample liquids were measured in-situ, at various times when ambient temperatures provided data over a suitable range. Data were recorded and the profiles were generated. These data were compared with acoustic data from the National Institute of Standards \& Technology and correlated very well. Subsequent validation of these profiles in the field has been conducted numerous times with multiple operators providing a high level of confidence in these data. All other liquids were characterized using the VCS platform. Molasses could not physically be measured (sound propagation at $1 \mathrm{MHz}$ was not possible) at room temperature and below in the VCS containment, thus the profile was generated from higher temperature points where acoustic velocity values could be measured and recorded. Appendix C provides the complete listing of 22 characterized liquids along with the VCS derived 2nd order polynomial fit equation for the velocitytemperature data. These equations are copied to the database text file where the PASS decision algorithms can access the file each time a temperature is entered and measurement is obtained. In this way, all field measurements taken with the PASS unit can be compared to the profiles generated in Phase 1 of this effort.

The results of this measurement exercise strongly demonstrate that by employing ultrasonic property measurements of acoustic velocity where the distance and temperature are suitably acquired, identification/discrimination/classification of liquids is possible. Data from ultrasonic velocity measurements as a function of temperature are presented, and analysis of these data indicates that accurate and consistent acoustic measurements were subsequently obtained for validation purposes using PASS technology from the outside of the container, non-invasively and nondestructively.

Ultrasonic energy can easily penetrate single-walled containers and has demonstrated a wide applicability toward measurement of metal, glass, plastic, ceramic and other materials where the air content in the material is nonexistent. Since ultrasonic energy does not propagate across air, container configurations that include air gaps, insulation, or double-walls will preclude the travel of ultrasonic energy into the container liquid contents. However, most standard commercially available liquids (from industrial chemicals and solvents to petroleum-based liquids and fuels) are packaged in single-walled metal or plastic containers, providing ample opportunities to employ ultrasonic energy in the measurement and detection of contraband or hidden items, liquid explosives and their precursors, other weapons of mass destruction liquids and dual-use, co-mingled mixtures and liquid constituents.

A review of the standard deviation and coefficient of variance statistics show that the VCS data and associated PASS data are well correlated and both reliable and consistent. It is evident that when interrogating smaller containers 12 in. in diameter and less, the accuracy of the time-of-flight measurements is reduced and the capability to identify liquids consistently in smaller containers will not 
be as effective as it would be with the same liquids in larger containers. Data to validate this was collected for water in larger 55-gallon drums at similar temperatures and plotted on the same VCSgenerated curve for water. A magnified portion of the curve is illustrated in Figure 7.1 where it is apparent that the PASS-measured data on larger containers will indeed converge toward the VCSgenerated profile.

The above observation is due to the effects of container wall thickness (and associated time-of-flight delays) relative to the overall time-of-flight across the diameter of the container. As the ratio of overall container diameter to wall thickness becomes larger, the impact of the walls on the resultant PASSmeasured velocities are less significant and the data begin to converge toward the line, which is essentially the true-state liquid velocity.

The variability in the VCS measurement system from run-to-run on the same liquid is extremely low and the relative accuracy of the data acquired with this system as referenced to water values is also quite good. Conversely, PASS field measurements are predicated upon many more variables that could substantially impact the resultant measurement. The container distance measurement must be accurately determined and the temperature of the liquid (via a container surface temperature measurement) should be obtained to within approximately \pm 3 to $4^{\circ} \mathrm{F}$ or the resultant velocity data may not be representative of the liquid inside the container. Thus, care must be taken to initiate PASS measurements with accurate inputs to the system, especially if the primary capability of this device is to be focused on identification (classification) of liquids, and particularly if the containers are 12 in. in diameter and smaller.

It is recommended that a second VCS container be fabricated from high-grade stainless steel with sufficient properties and characteristics to hold acids and other caustic and volatile liquids that may be targeted for Phase 2 database additions. The current aluminum containment is not suitable for these types of liquids.

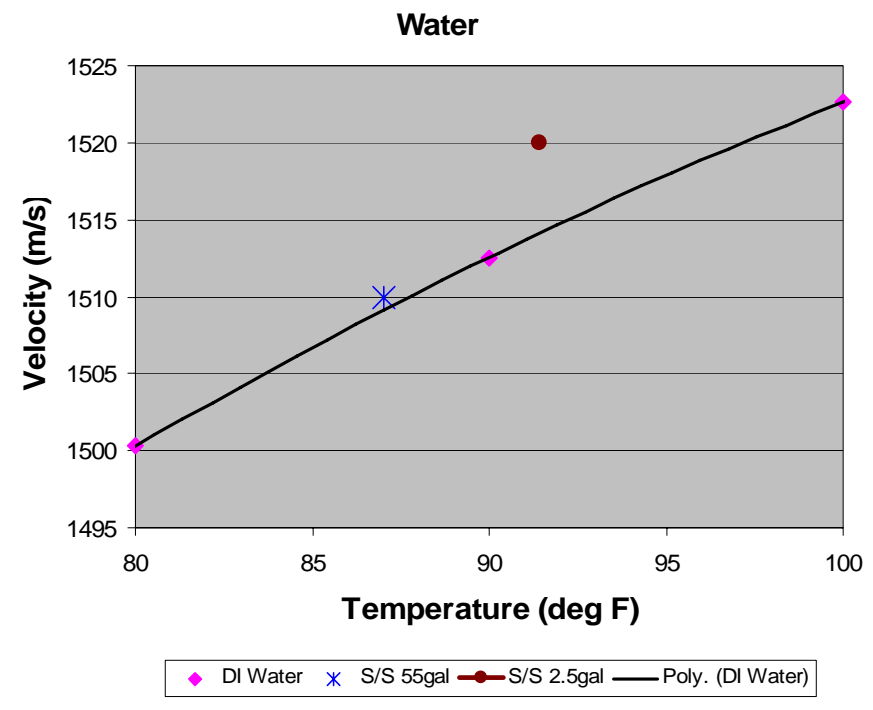

Figure 7.1. Example Data Acquired on Water (at approximately $90^{\circ} \mathrm{F}$ ) in Two Different Sized Containers, a Stainless Steel 55-Gallon Drum and a 2.5-Gallon Stainless Steel Container. 


\subsection{PNNL Management and Technical Points of Contact}

Steve Martin - Product Line Manager

Protection, Interdiction and Enforcement Technologies

National Security Directorate (NSD)

Pacific Northwest National Laboratory

902 Battelle Blvd MSIN: K8-21

Richland, Washington 99352

Phone: 509-372-4086

Fax: 509-375-2484

Email: steve.martin@pnl.gov

Technical Point of Contact: Principal Scientist and Project Manager

Aaron Diaz - Staff Scientist

National Security Directorate (NSD)

Applied Physics and Materials Characterization Sciences Group

Pacific Northwest National Laboratory

2400 Stevens Drive MSIN: K5-26

Richland, Washington 99352

Phone: 509-375-2606

Fax: 509-375-6497

Email: aaron.diaz@pnl.gov

Management and Administration Point of Contact:

Todd Samuel - Certified Project Manager (PMP) and Technical Group Manager

Energy Science \& Technology Directorate (ETD)

Technology Planning and Deployment Group

Pacific Northwest National Laboratory

902 Battelle Blvd MSIN: K6-05

Richland, Washington 99352

Phone: 509-375-6707

Fax: 509-372-4370

Email: todd.samuel@pnl.gov 


\section{Appendix A - List of Liquids Chosen for Acoustic Characterization in the PHASE 1 PACD Database}





\section{Appendix A - List of Liquids Chosen for Acoustic Characterization in the PHASE 1 PACD Database}

\begin{tabular}{|c|}
\hline Liquid \\
\hline SAE 30 Motor Oil \\
\hline 10W-40 Motor Oil \\
\hline Gasoline-87 Octane \\
Gasoline-92 Octane \\
\hline Low-Grade Camping Kerosene (1-K) \\
\hline Jet A Aviation Fuel \\
\hline Marine Diesel \\
\hline Diesel \#2 \\
\hline Benzene \\
\hline Methylene Chloride \\
\hline n-Hexane \\
\hline Chloroform \\
\hline Xylene \\
\hline Antifreeze \\
\hline \\
\hline Molasses \\
\hline Olive Oil \\
\hline Balsamic Vinegar \\
\hline Water \\
\hline Ethanol \\
\hline Methanol \\
\hline \\
\hline Liquid Chlorine (Compressed) \\
\hline Liquid Propane (Compressed) \\
\hline
\end{tabular}


A. 2 


\section{Appendix B - Excel Plots Illustrating the Acoustic Velocity- Temperature Profiles for each Liquid}





\section{Appendix B - Excel Plots Illustrating the Acoustic Velocity- Temperature Profiles for each Liquid}

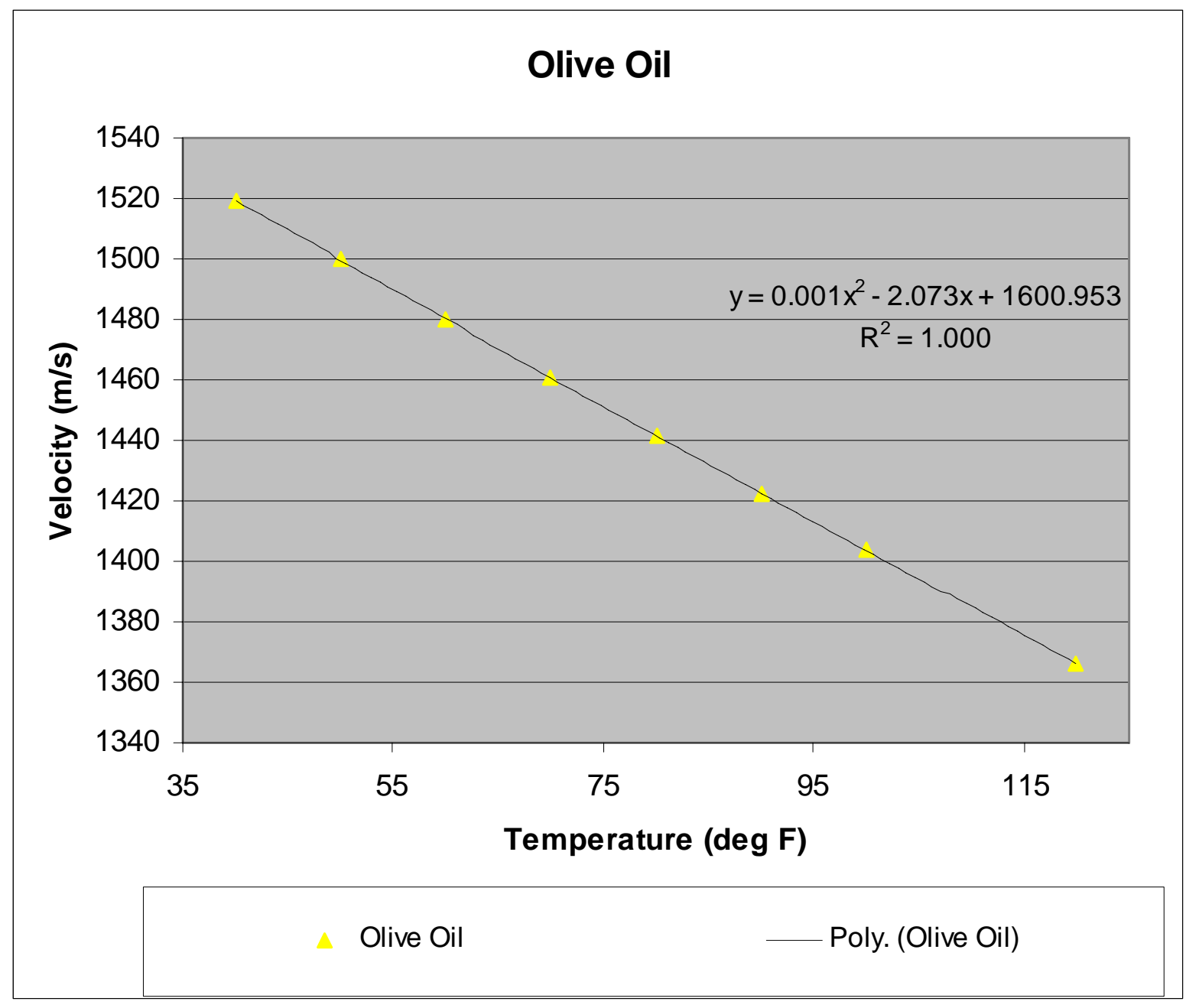

Figure B.1. Acoustic Velocity-Temperature Profile for Olive Oil 


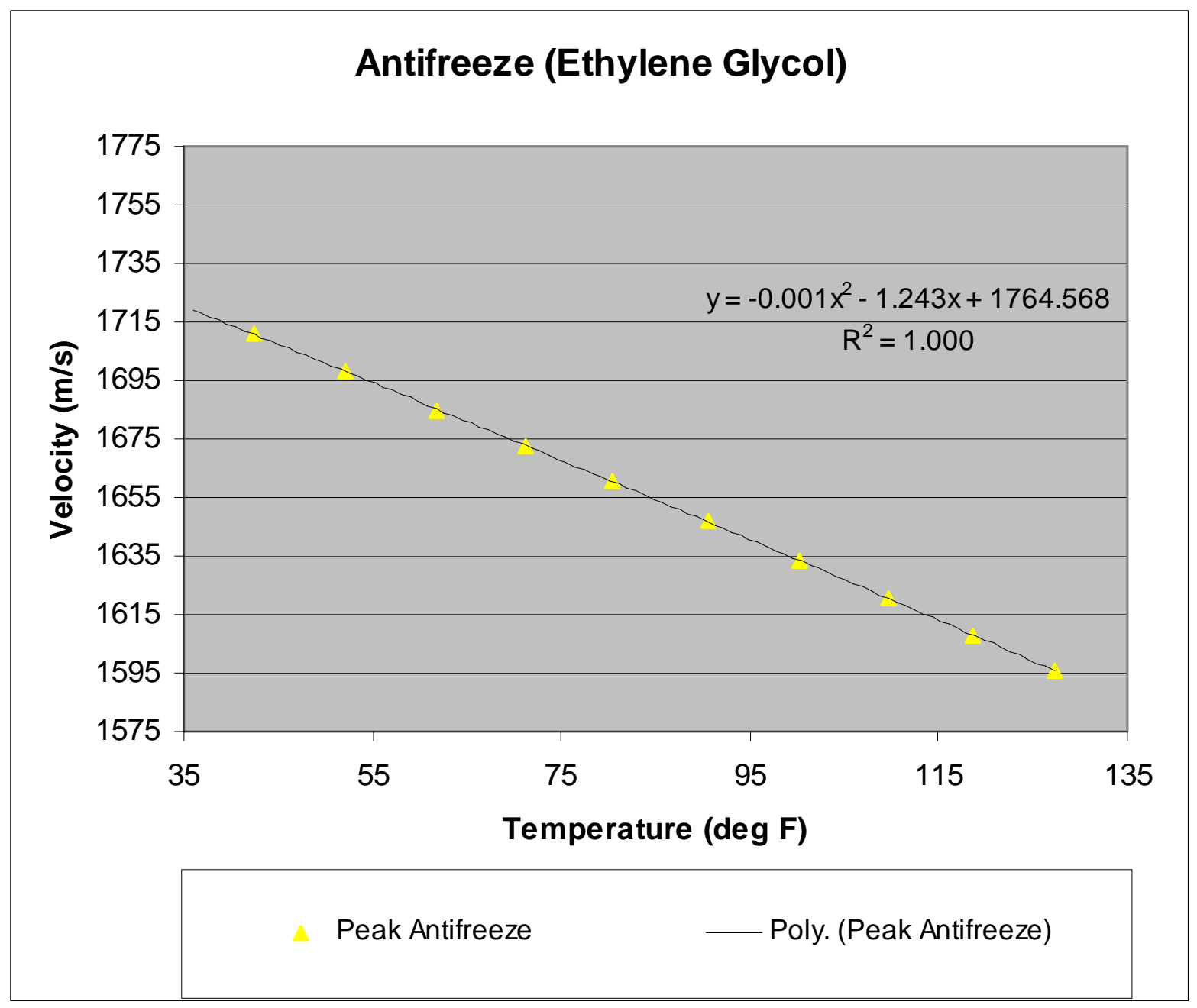

Figure B.2. Acoustic Velocity-Temperature Profile for Antifreeze (Ethylene Glycol) 


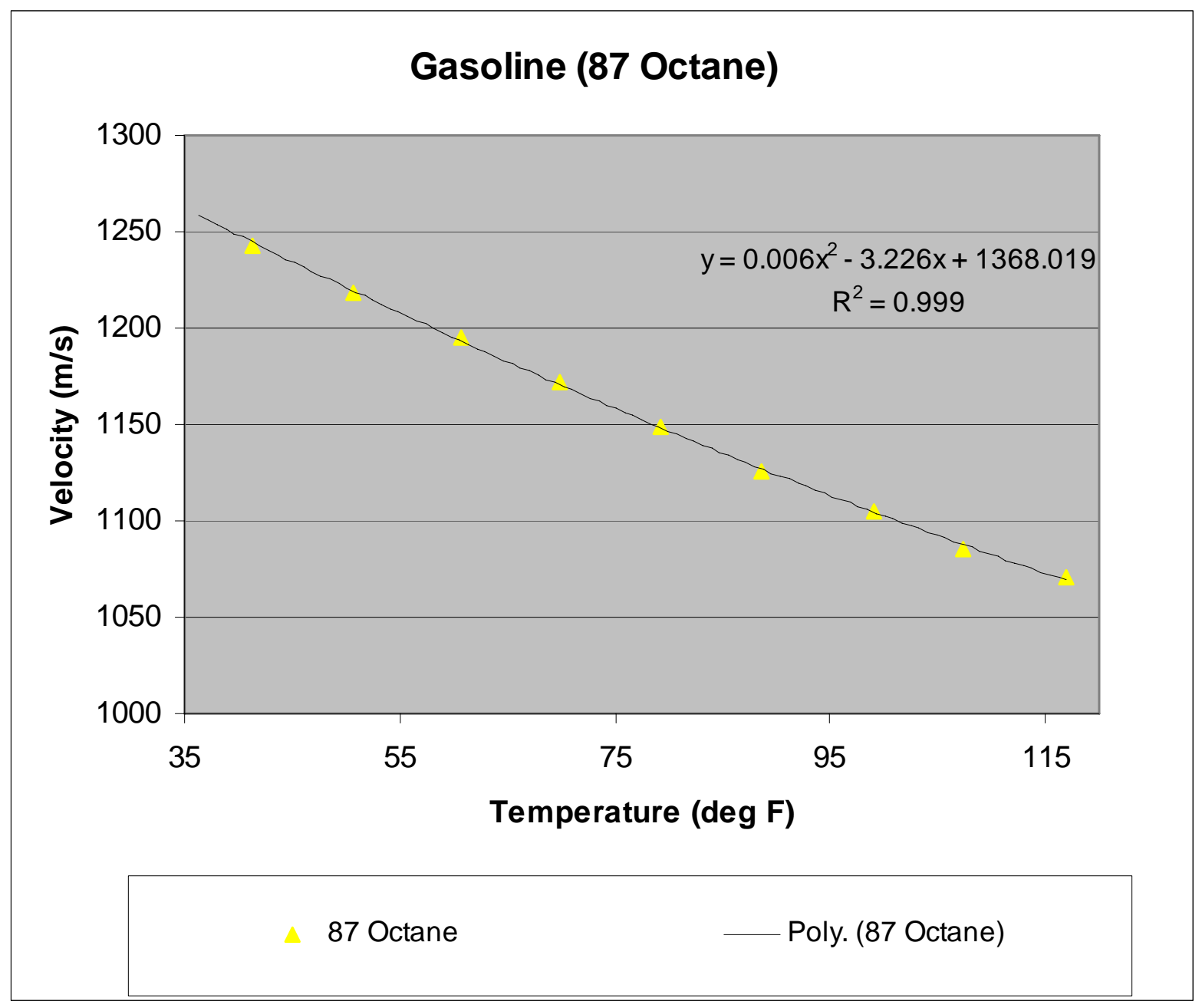

Figure B.3. Acoustic Velocity-Temperature Profile for Gasoline (87 Octane) 


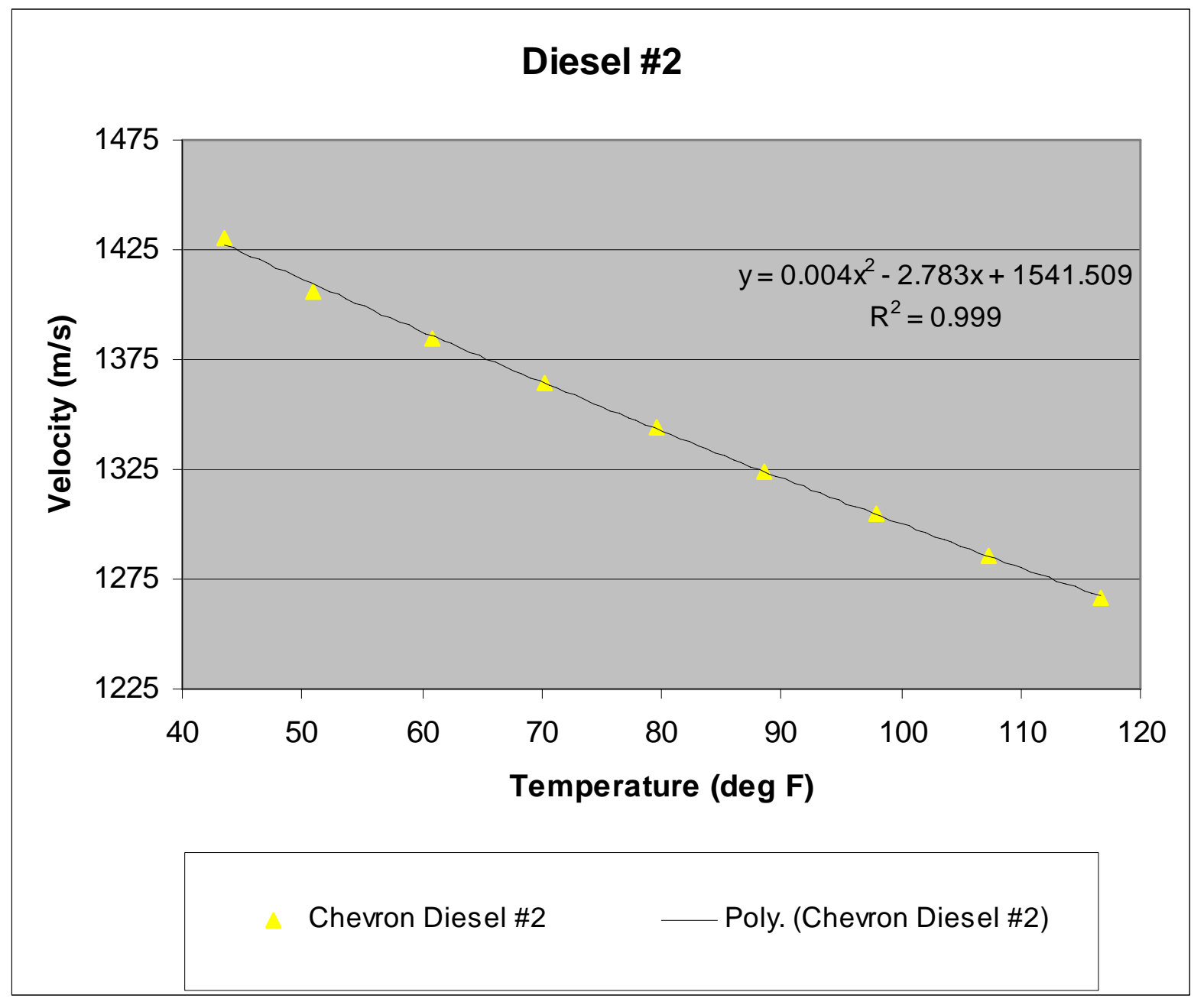

Figure B.4. Acoustic Velocity-Temperature Profile for Diesel No. 2 


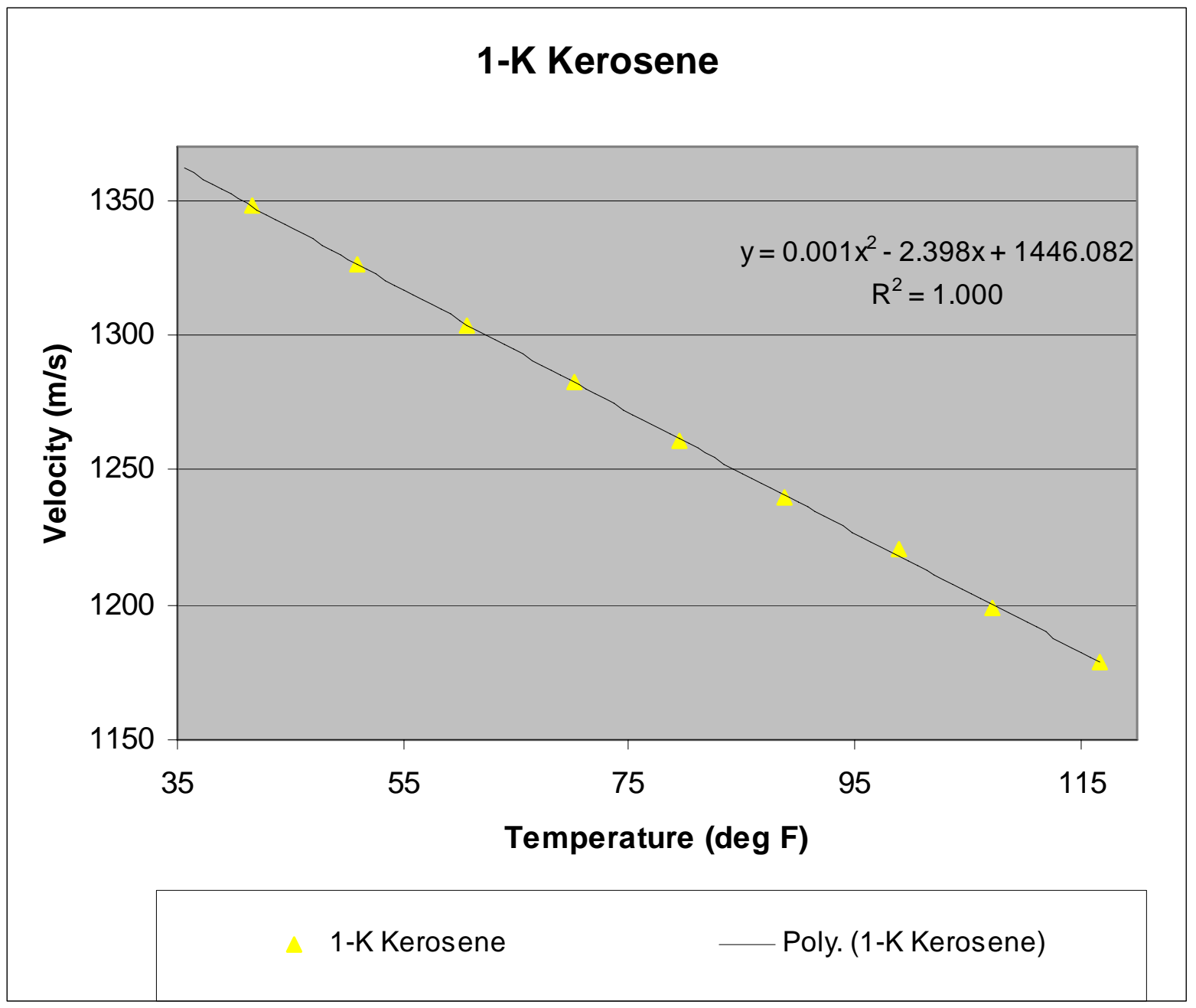

Figure B.5. Acoustic Velocity-Temperature Profile for Low Grade Kerosene (Camping Fuel, 1-K) 


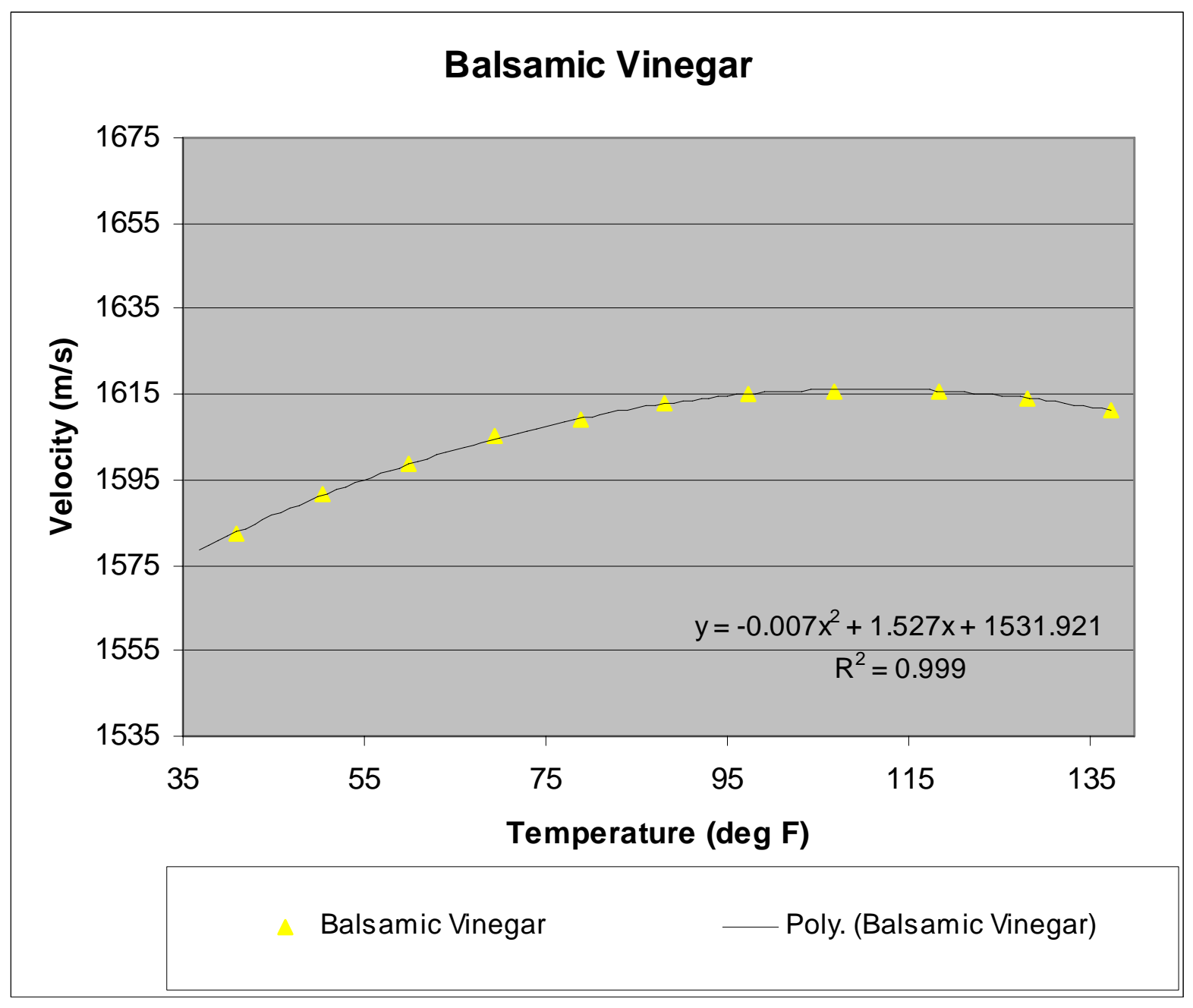

Figure B.6. Acoustic Velocity-Temperature Profile for Balsamic Vinegar 


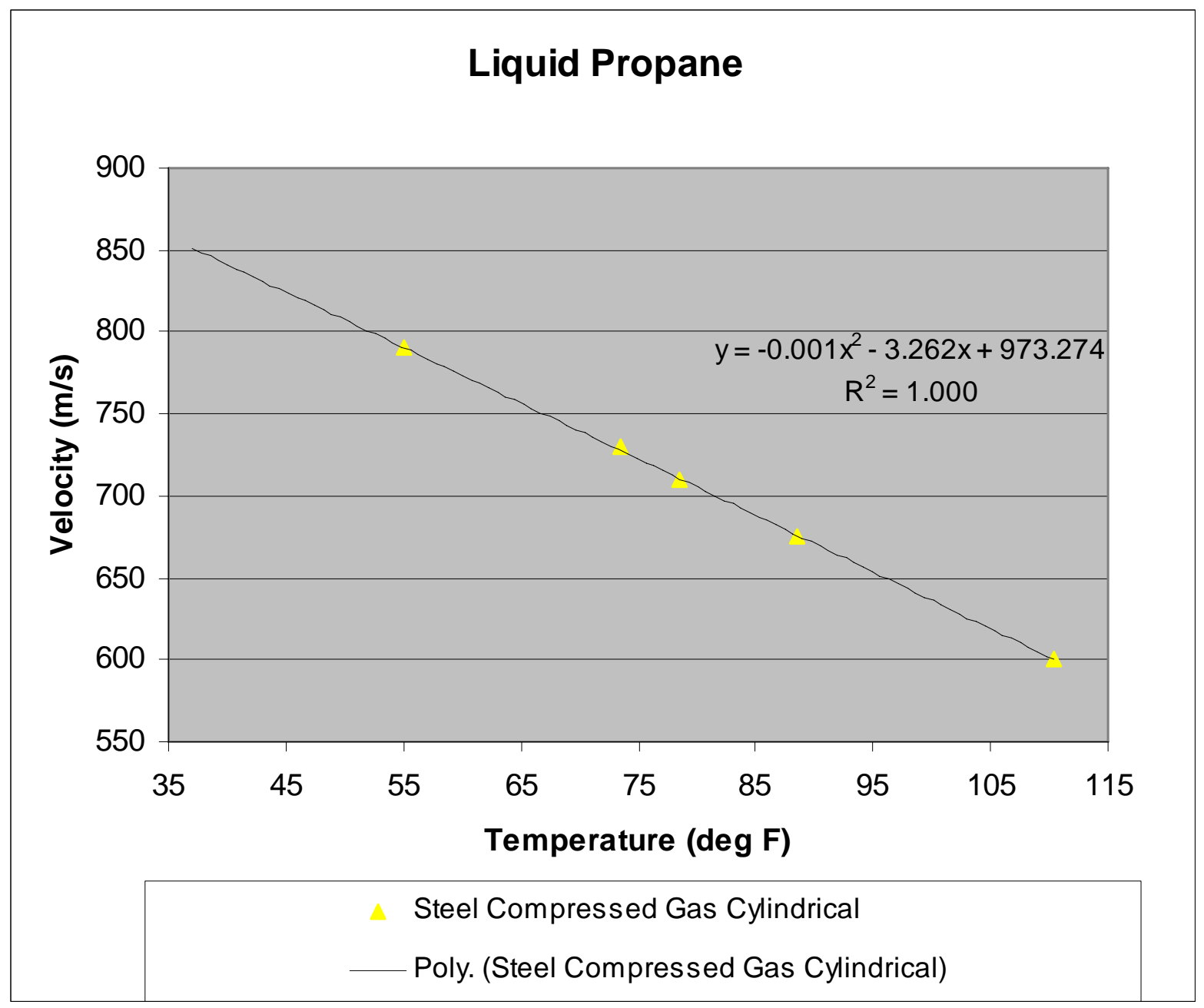

Figure B.7. Acoustic Velocity-Temperature Profile for Liquid Propane (Compressed) 


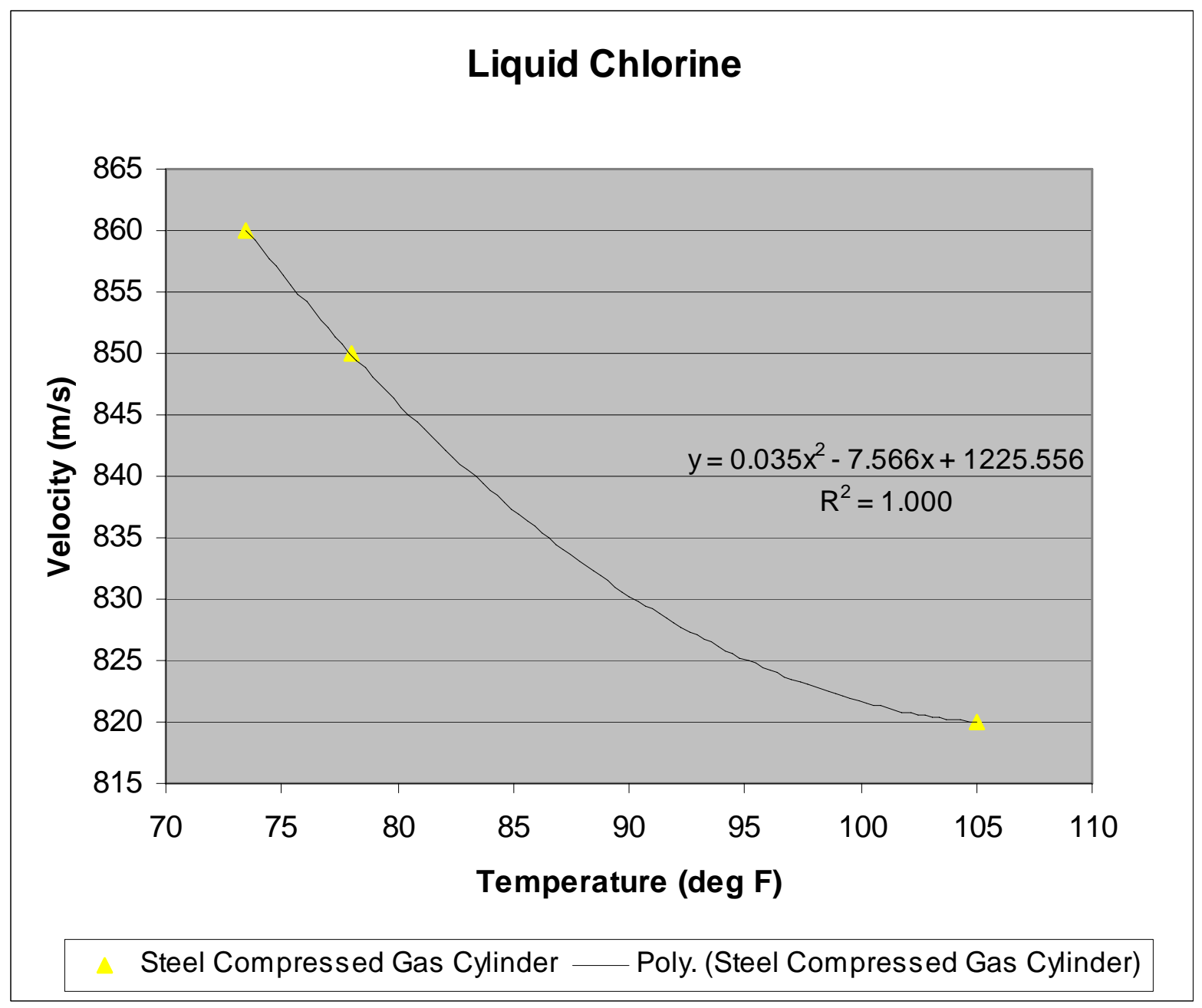

Figure B.8. Acoustic Velocity-Temperature Profile for Liquid Chlorine (Compressed) 


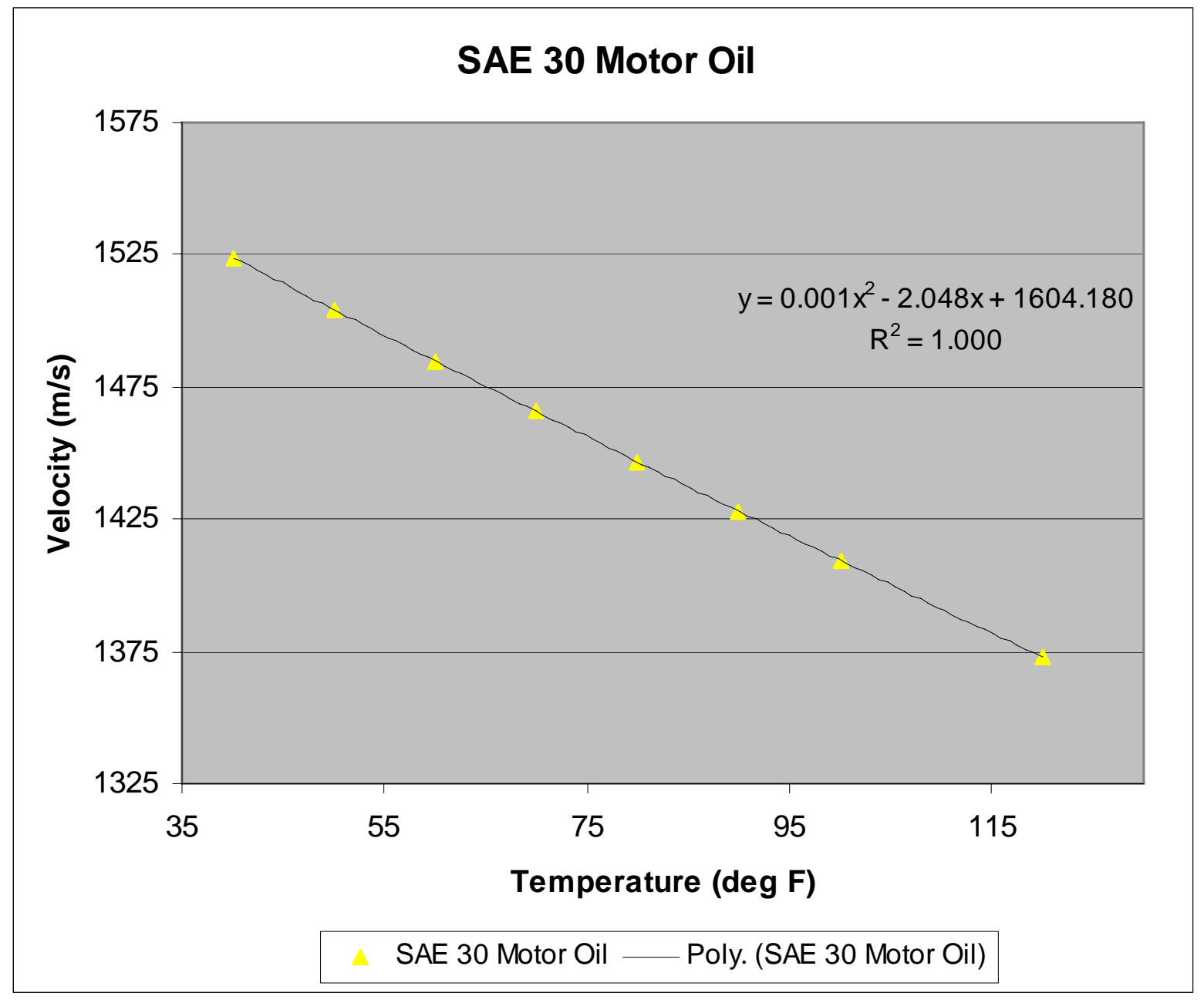

Figure B.9. Acoustic Velocity-Temperature Profile for SAE 30 Motor Oil 


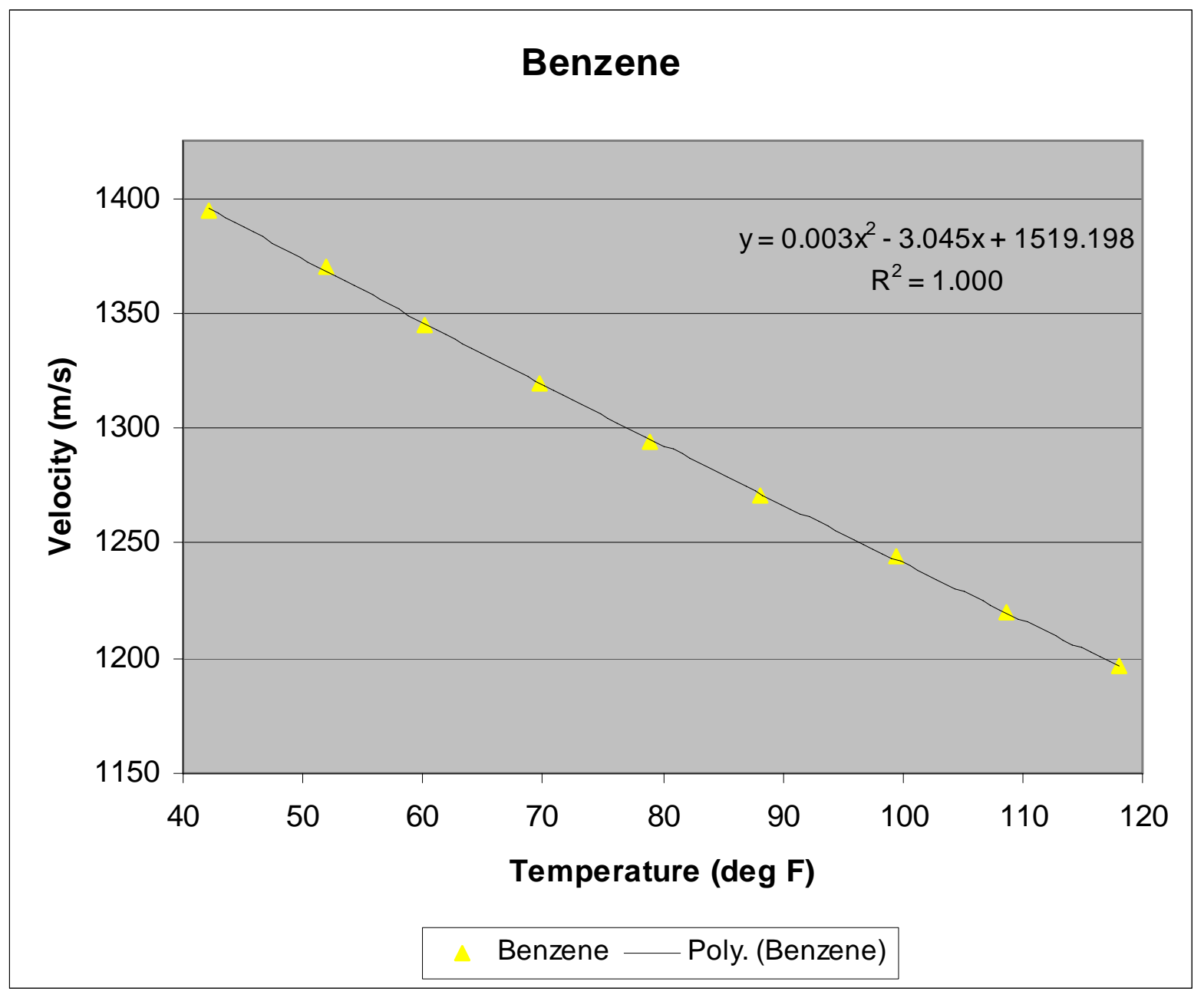

Figure B.10. Acoustic Velocity-Temperature Profile for Benzene 


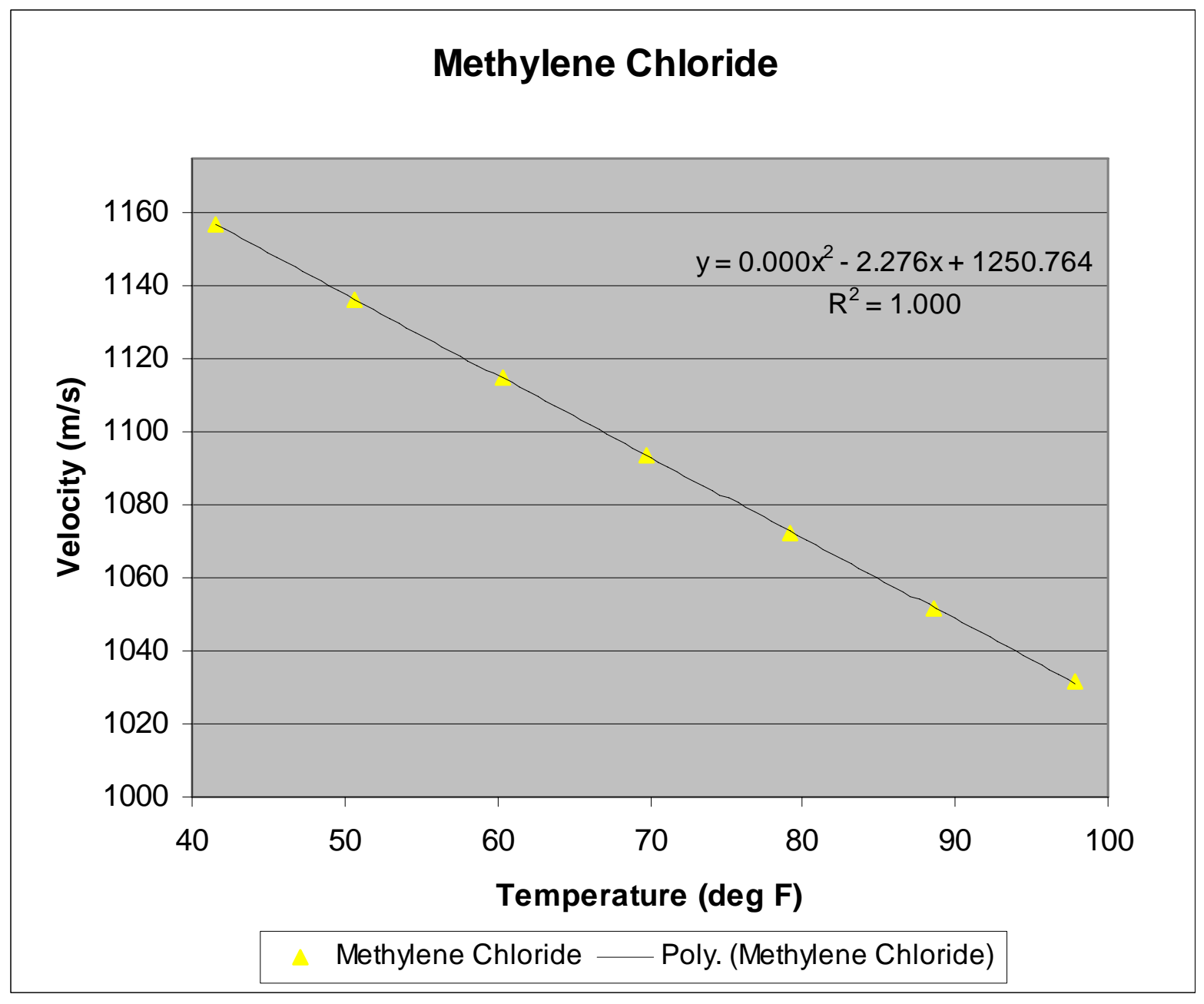

Figure B.11. Acoustic Velocity-Temperature Profile for Methylene Chloride 


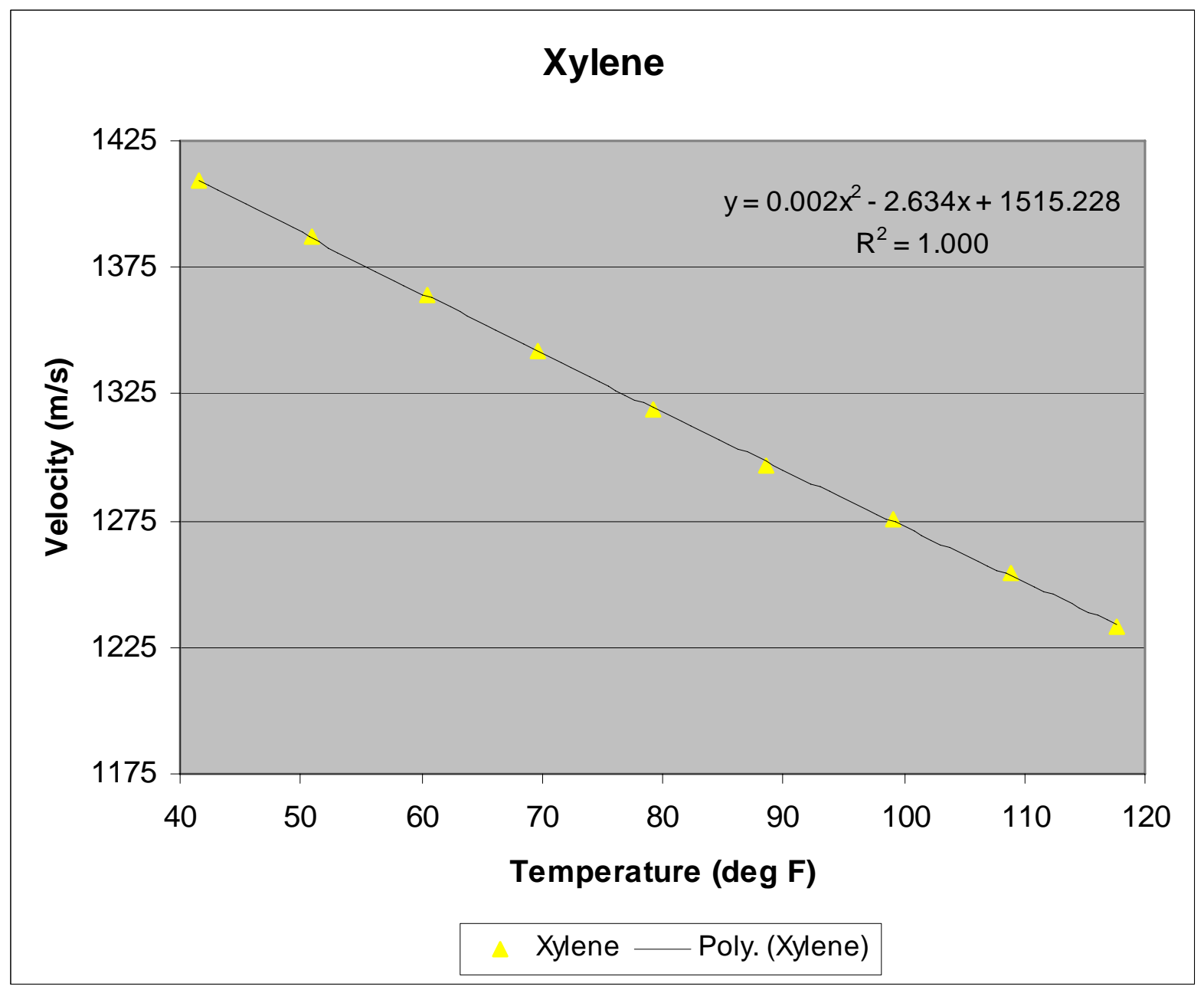

Figure B.12. Acoustic Velocity-Temperature Profile for Xylene 


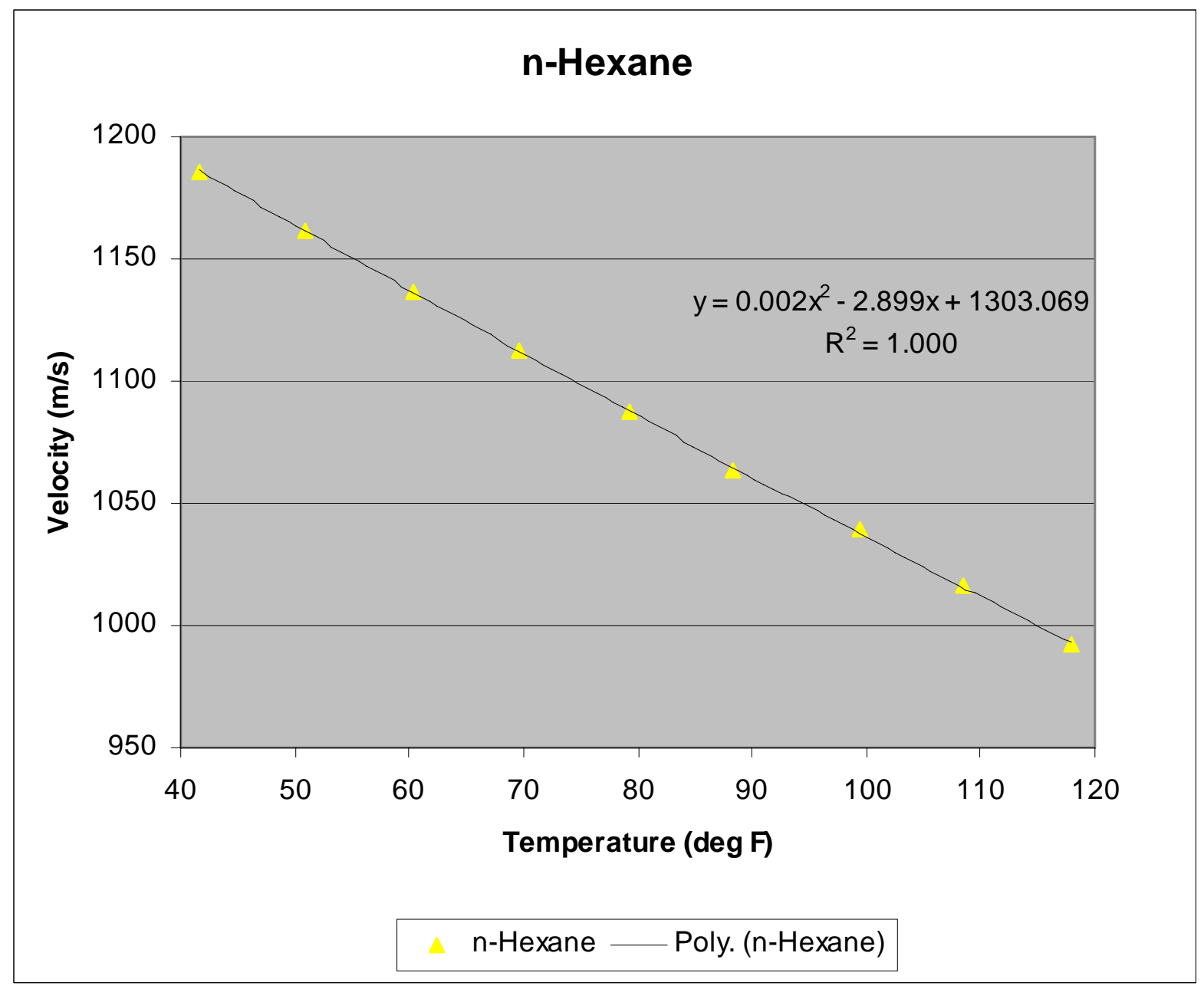

Figure B.13. Acoustic Velocity-Temperature Profile for n-Hexane 


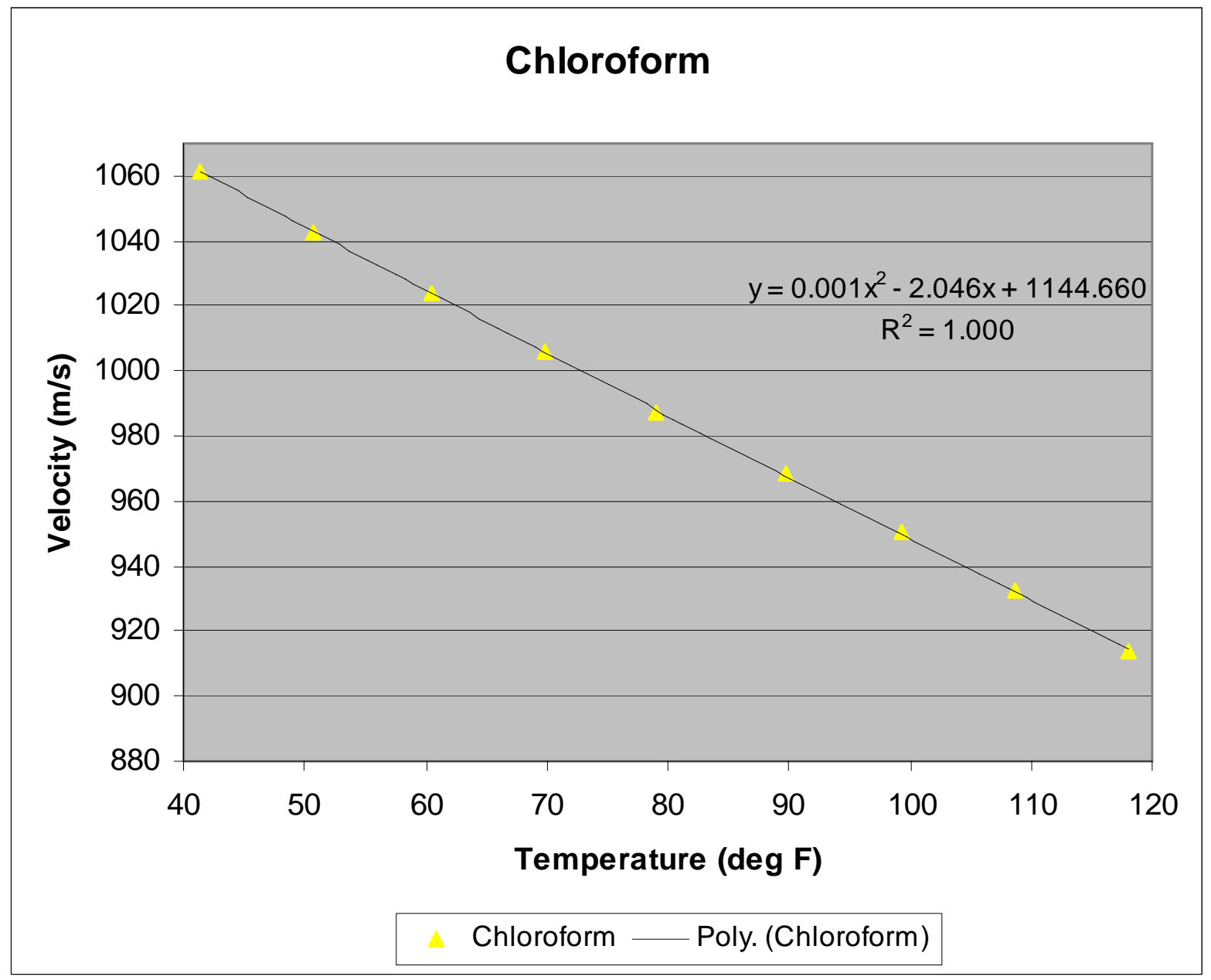

Figure B.14. Acoustic Velocity-Temperature Profile for Chloroform 


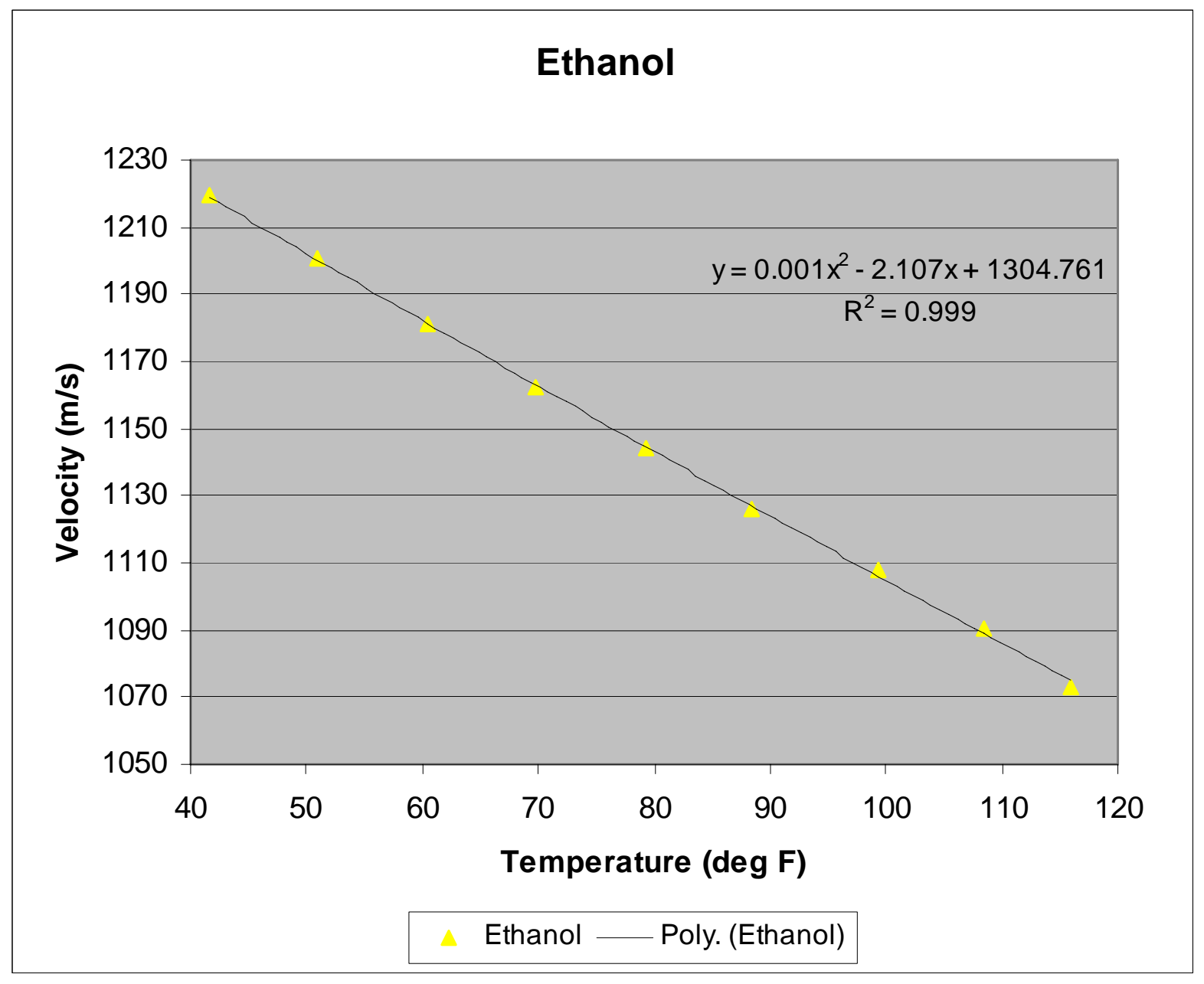

Figure B.15. Acoustic Velocity-Temperature Profile for Ethanol 


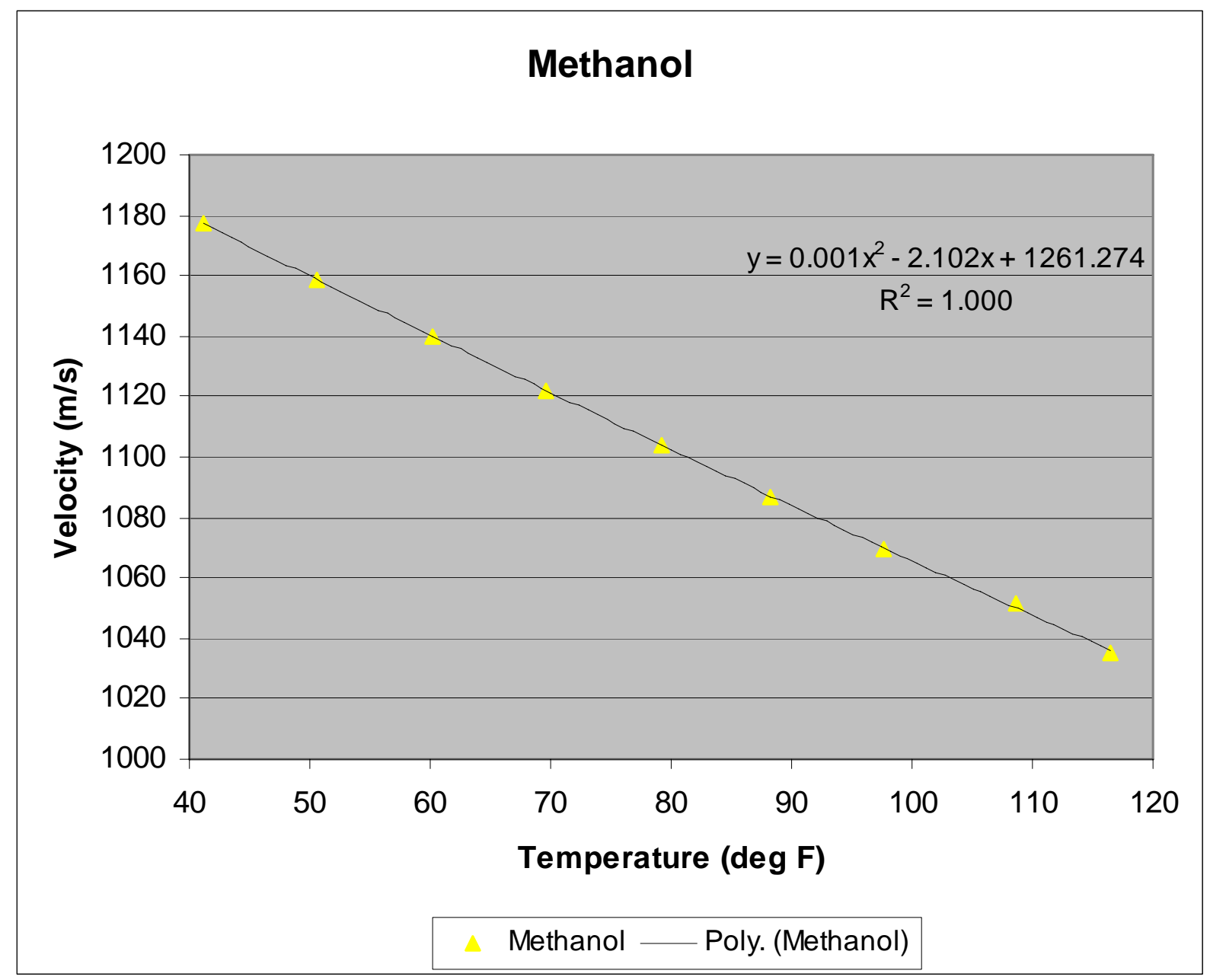

Figure B.16. Acoustic Velocity-Temperature Profile for Methanol 


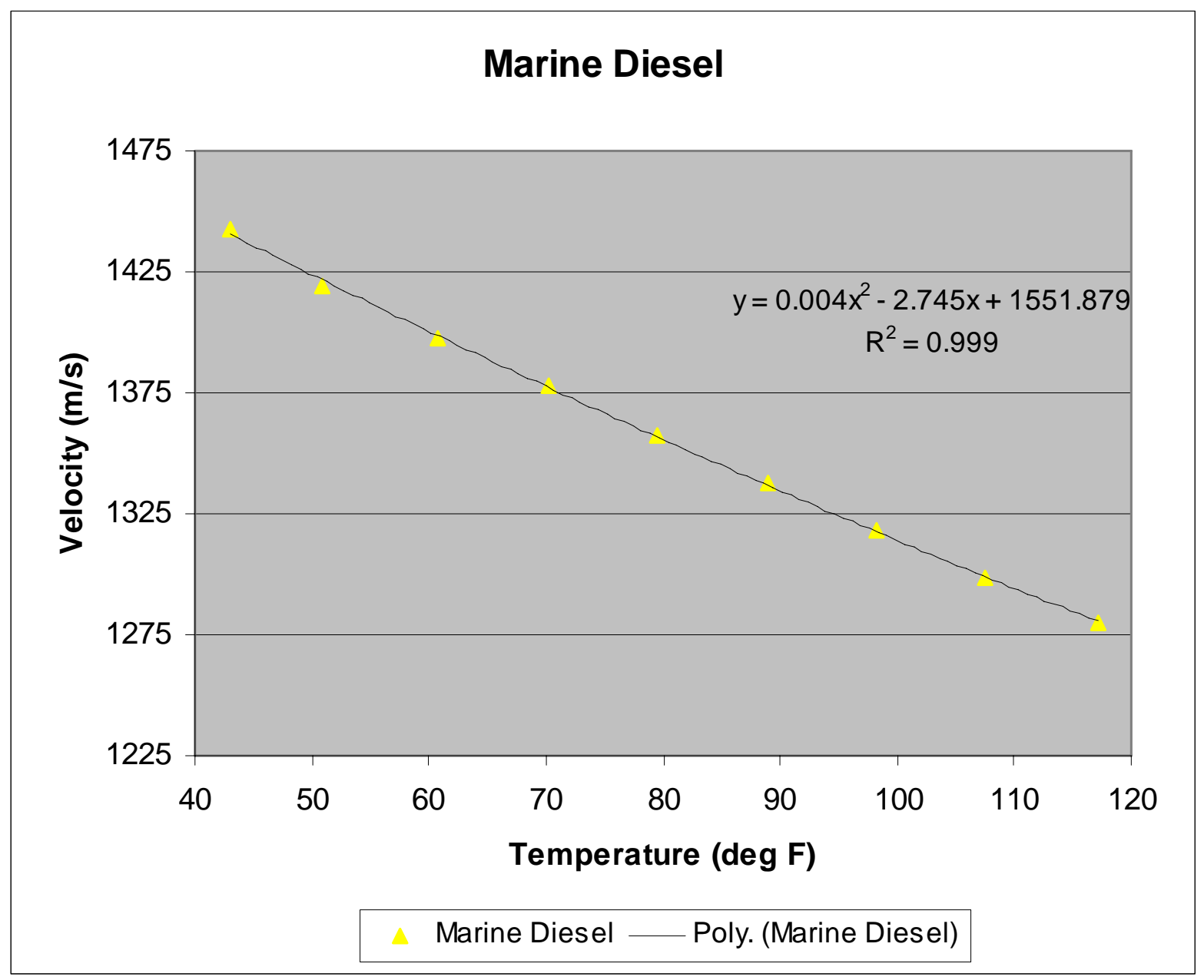

Figure B.17. Acoustic Velocity-Temperature Profile for Marine Diesel 


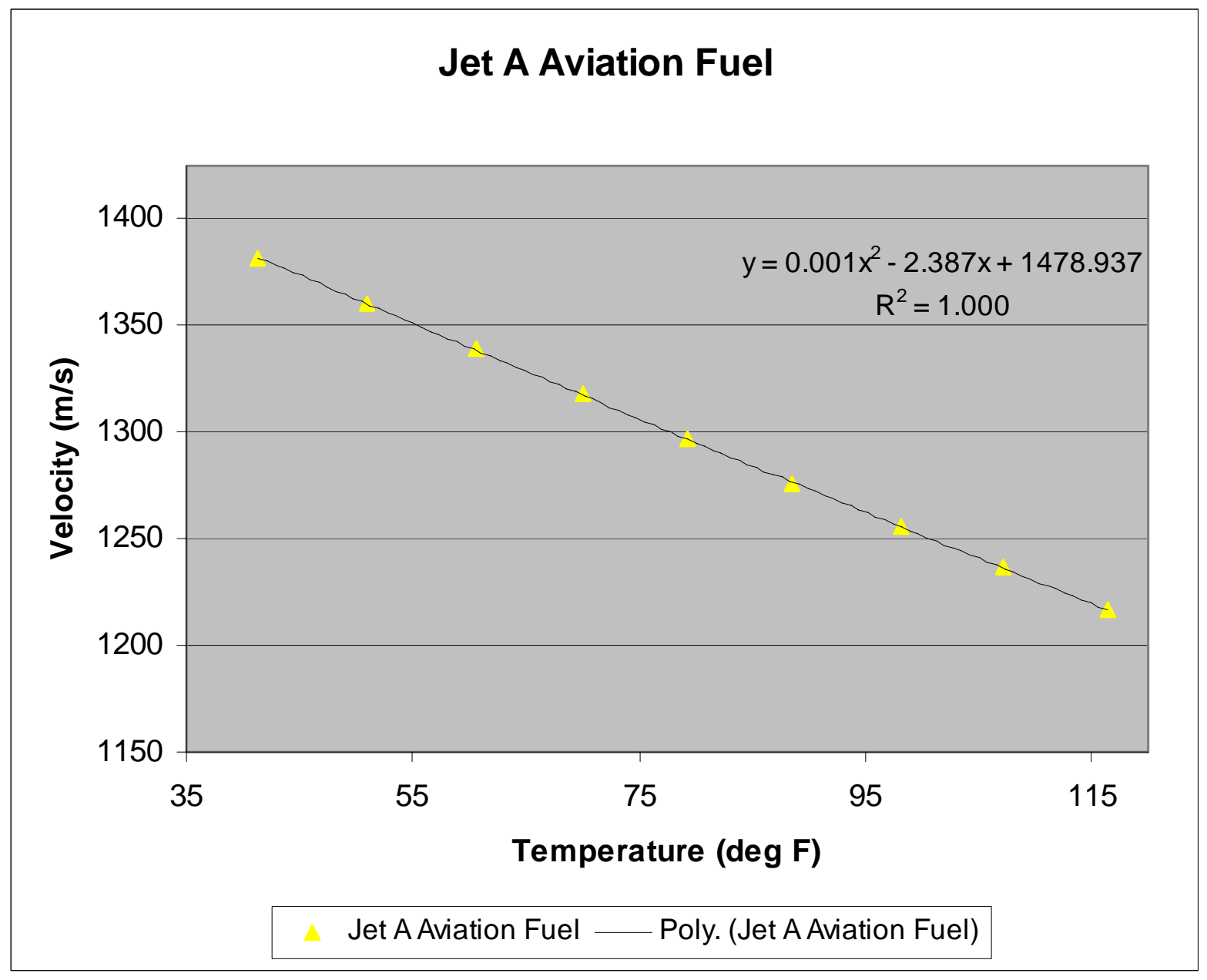

Figure B.18. Acoustic Velocity-Temperature Profile for Jet Fuel (Type A) 


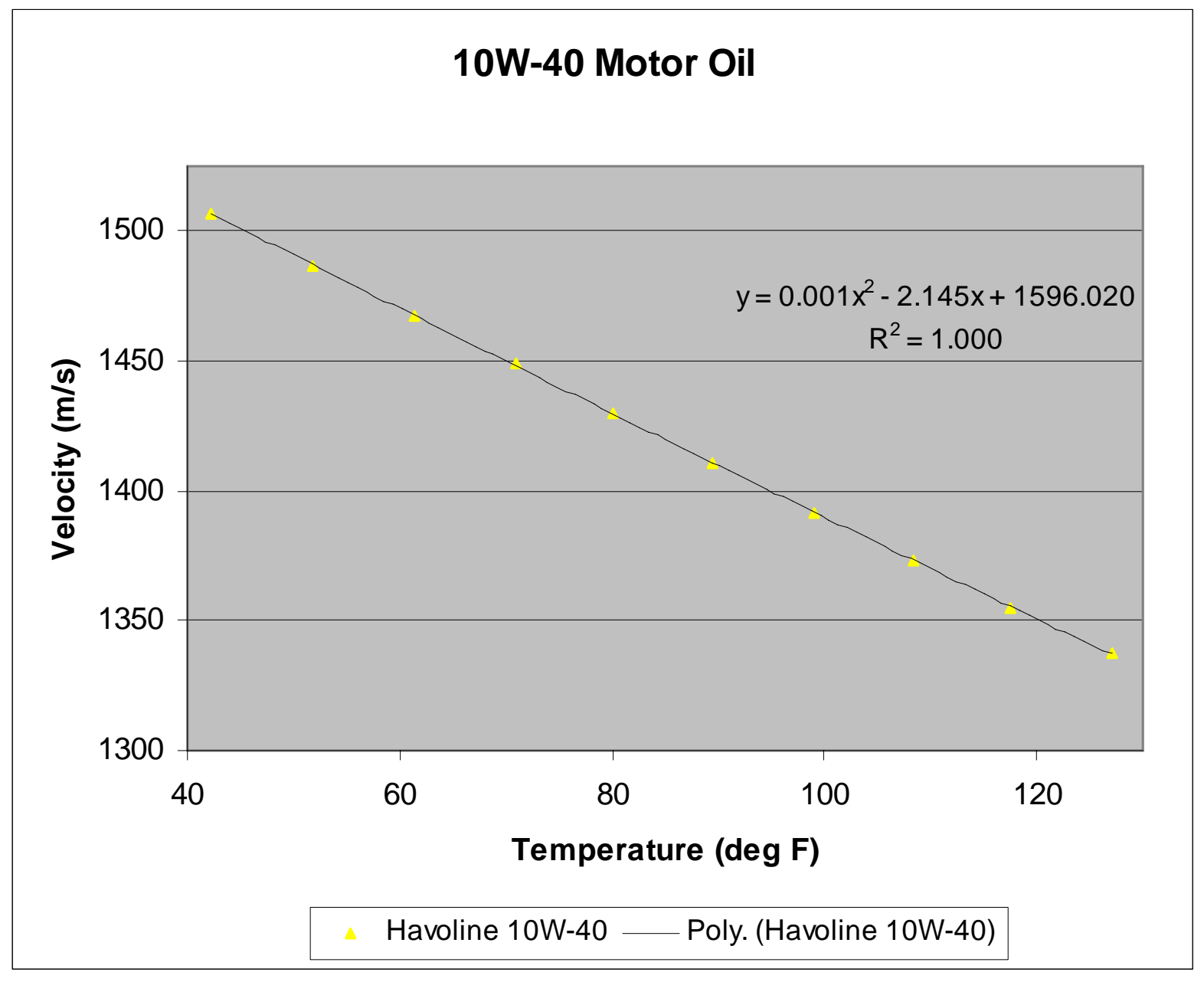

Figure B.19. Acoustic Velocity-Temperature Profile for 10W-40 Motor Oil 


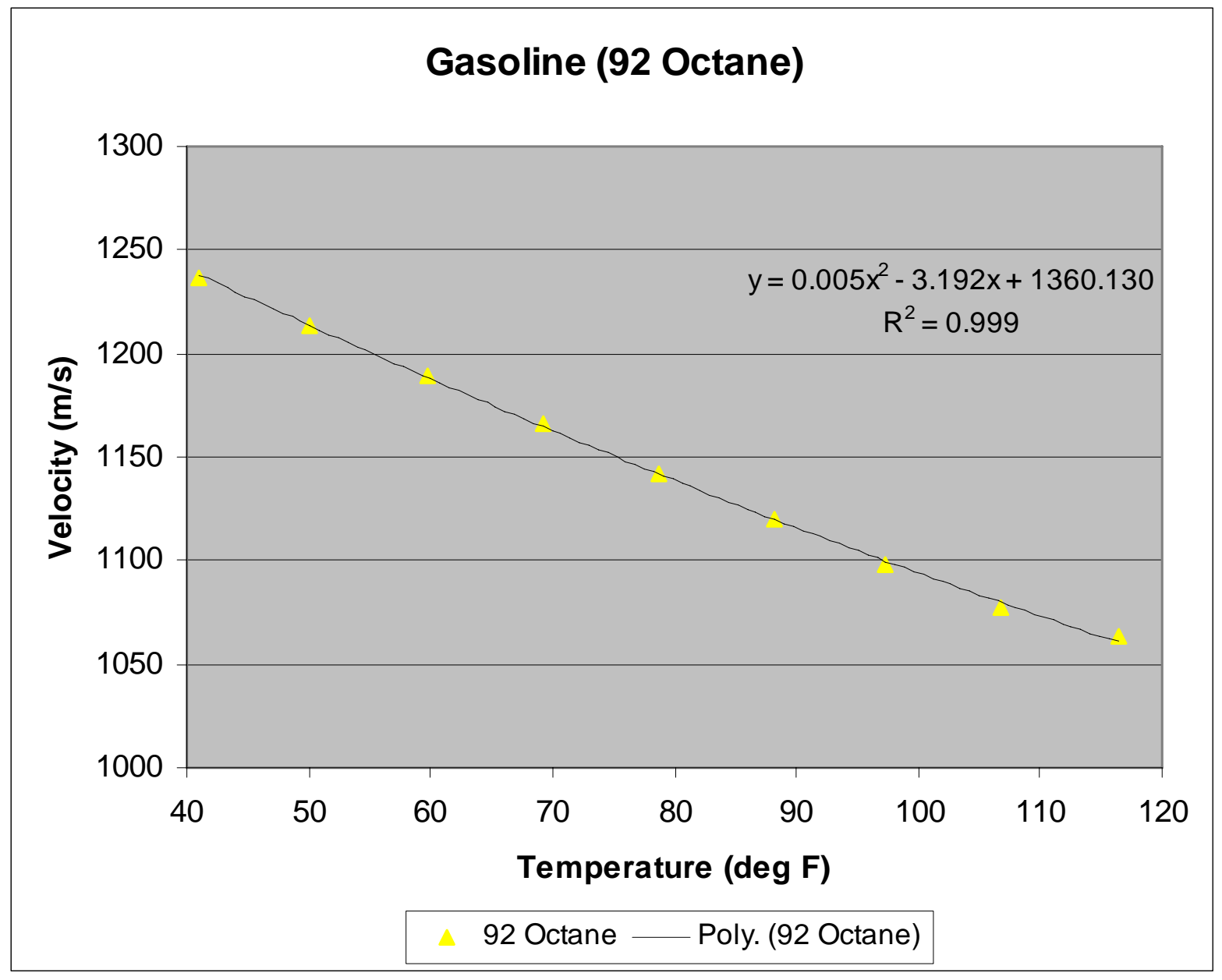

Figure B.20. Acoustic Velocity-Temperature Profile for Gasoline (92 Octane) 


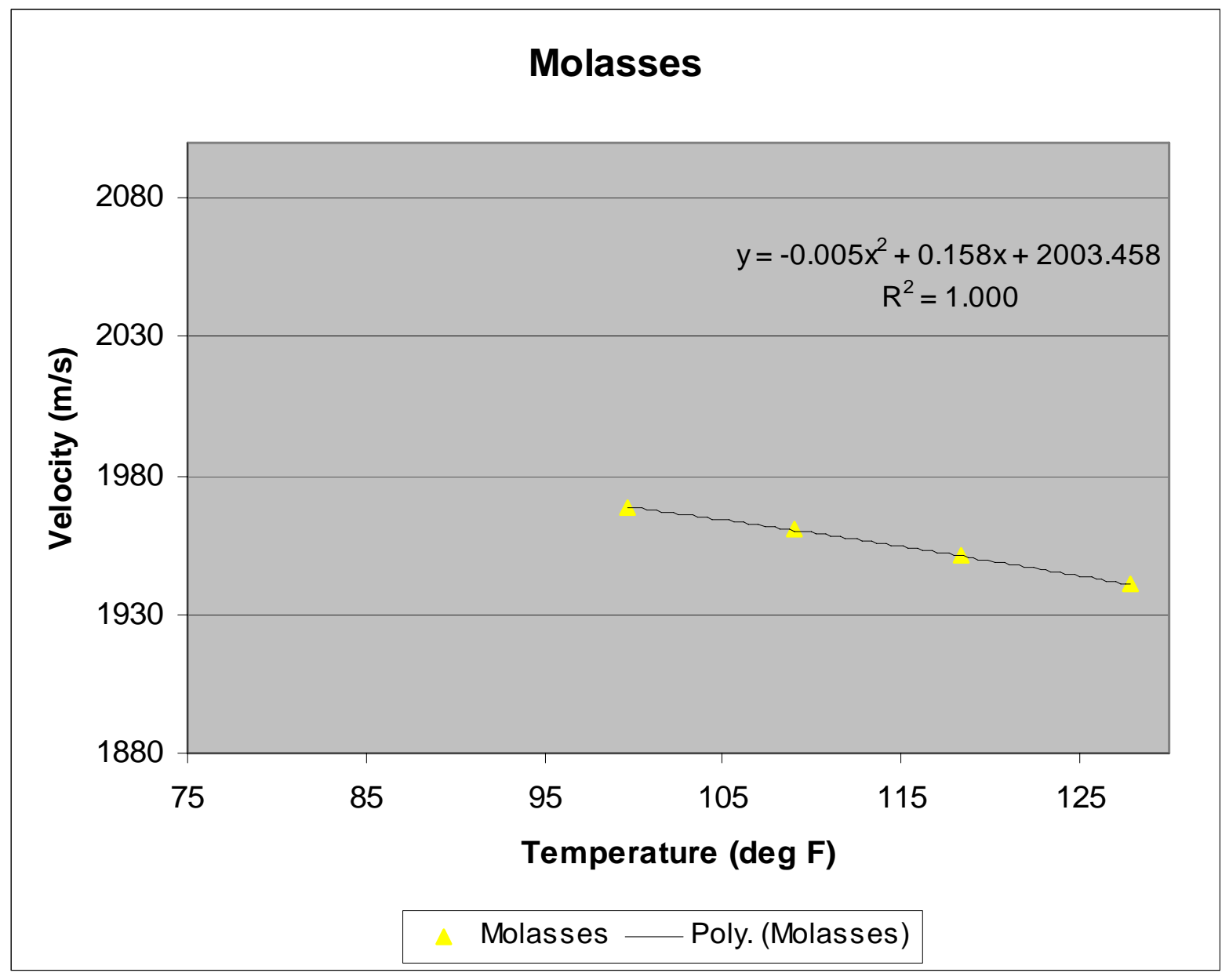

Figure B.21. Acoustic Velocity-Temperature Profile for Molasses 


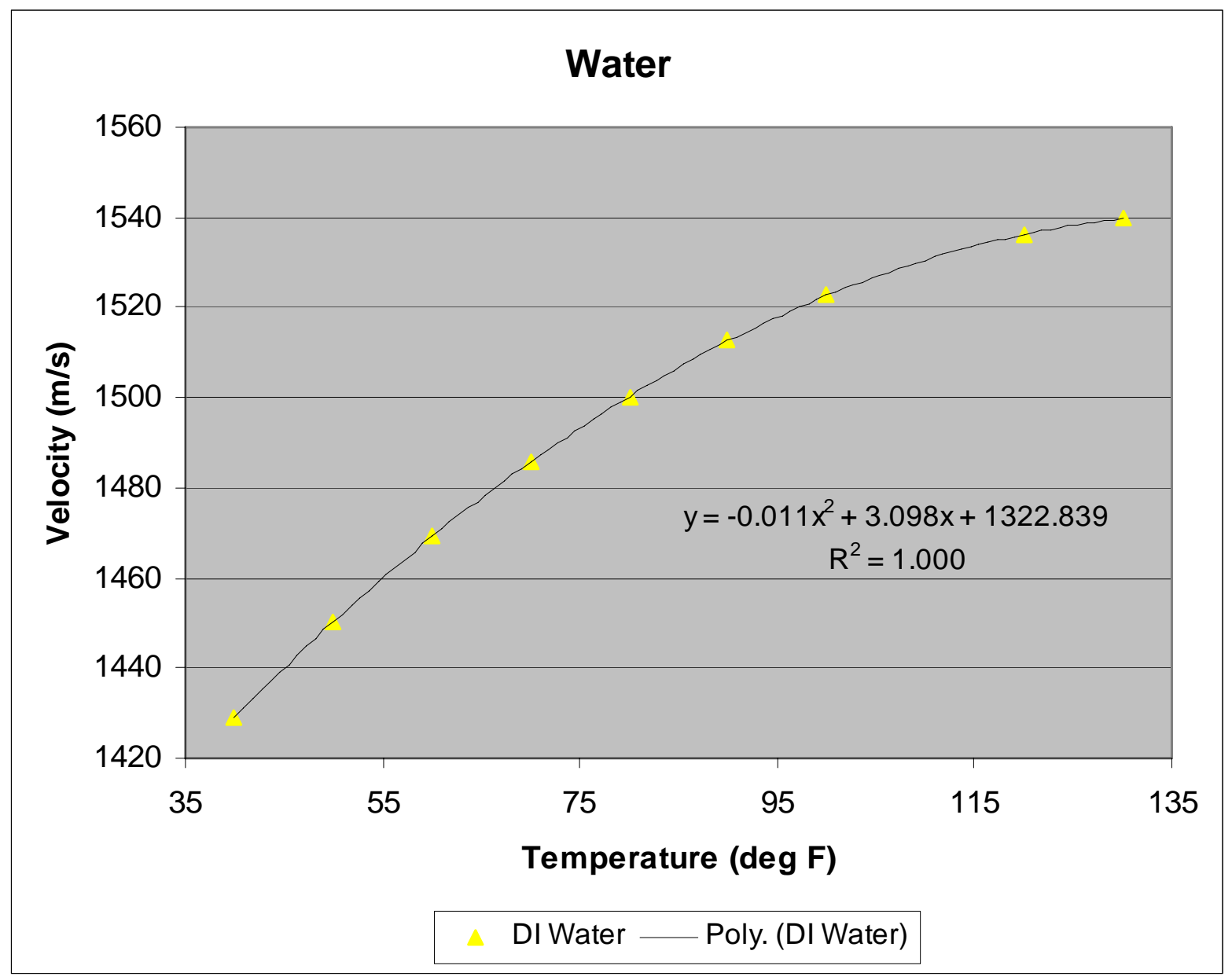

Figure B.22. Acoustic Velocity-Temperature Profile for Water 
Appendix C - Final PHASE 1 Database Listing of Liquids and Associated 2nd Order Polynomial Fit Equations 



\section{Appendix C - Final PHASE 1 Database Listing of Liquids and Associated 2nd Order Polynomial Fit Equations}

\begin{tabular}{|l|c|c||}
\hline \multicolumn{1}{|c|}{ Liquid } & $\begin{array}{c}\text { Second Order Polynomial Fit; } \\
\text { where } \mathbf{X}=\text { Temperature in }\end{array}$ & $\mathbf{R}^{2}$ Value \\
\hline SAE 30 Motor Oil & $\mathrm{y}=0.001 \mathrm{x}^{2}-2.048 \mathrm{x}+1604.180$ & 1.000 \\
\hline 10W-40 Motor Oil & $\mathrm{y}=0.001 \mathrm{x}^{2}-2.145 \mathrm{x}+1596.020$ & 1.000 \\
\hline Gasoline-87 Octane & $\mathrm{y}=0.006 \mathrm{x}^{2}-3.226 \mathrm{x}+1368.019$ & 0.999 \\
\hline Gasoline-92 Octane & $\mathrm{y}=0.005 \mathrm{x}^{2}-3.192 \mathrm{x}+1360.130$ & 0.999 \\
\hline Kerosene (1K) & $\mathrm{y}=0.001 \mathrm{x}^{2}-2.398 \mathrm{x}+1446.082$ & 1.000 \\
\hline Jet A Aviation Fuel & $\mathrm{y}=0.001 \mathrm{x}^{2}-2.387 \mathrm{x}+1478.937$ & 1.000 \\
\hline Marine Diesel & $\mathrm{y}=0.004 \mathrm{x}^{2}-2.745 \mathrm{x}+1551.879$ & 0.999 \\
\hline Diesel \#2 & $\mathrm{y}=0.004 \mathrm{x}^{2}-2.783 \mathrm{x}+1541.509$ & 0.999 \\
\hline & & 1.000 \\
\hline Benzene & $\mathrm{y}=0.003 \mathrm{x}^{2}-3.045 \mathrm{x}+1519.198$ & 1.000 \\
\hline Methylene Chloride & $\mathrm{y}=0.000 \mathrm{x}^{2}-2.276 \mathrm{x}+1250.764$ & 1.000 \\
\hline $\mathrm{n}$-Hexane & $\mathrm{y}=0.002 \mathrm{x}^{2}-2.899 \mathrm{x}+1303.069$ & 1.000 \\
\hline Chloroform & $\mathrm{y}=0.001 \mathrm{x}^{2}-2.046 \mathrm{x}+1144.660$ & 1.000 \\
\hline Xylene & $\mathrm{y}=0.002 \mathrm{x}^{2}-2.634 \mathrm{x}+1515.228$ & 1.000 \\
\hline Antifreeze & $\mathrm{y}=-0.001 \mathrm{x}^{2}-1.243 \mathrm{x}+1764.568$ & 1.000 \\
\hline & & 1.000 \\
\hline Molasses & $\mathrm{y}=-0.005 \mathrm{x}^{2}+0.158 \mathrm{x}+2003.458$ & 1.000 \\
\hline Olive Oil & $\mathrm{y}=0.001 \mathrm{x}^{2}-2.073 \mathrm{x}+1600.953$ & 1.000 \\
\hline Balsamic Vinegar & $\mathrm{y}=-0.007 \mathrm{x}^{2}+1.527 \mathrm{x}+1531.921$ & 0.999 \\
\hline Water & $\mathrm{y}=-0.011 \mathrm{x}^{2}+3.098 \mathrm{x}+1322.839$ & 1.000 \\
\hline & $\mathrm{y}=0.035 \mathrm{x}^{2}-7.566 \mathrm{x}+1225.556$ & \\
\hline Ethanol & $\mathrm{y}=-0.001 \mathrm{x}^{2}-3.262 \mathrm{x}+973.274$ & \\
\hline Methanol & $\mathrm{y}=0.001 \mathrm{x}^{2}-2.102 \mathrm{x}+1261.274$ & \\
\hline & & \\
\hline Liquid Chlorine & & \\
\hline Liquid Propane & & \\
\hline
\end{tabular}

Figure C.1. Second Order Polynomial Fits, where $X=$ Temperature in ${ }^{\circ} \mathrm{F}$, for all liquids characterized in Phase 1. 


$$
\text { C. } 2
$$




\section{Appendix D - Excel Plots of Database Validation Data on Subset of Liquids for Various Containers Across Multiple Temperature Points}





\section{Appendix D - Excel Plots of Database Validation Data on Subset of Liquids for Various Containers Across Multiple Temperature Points}

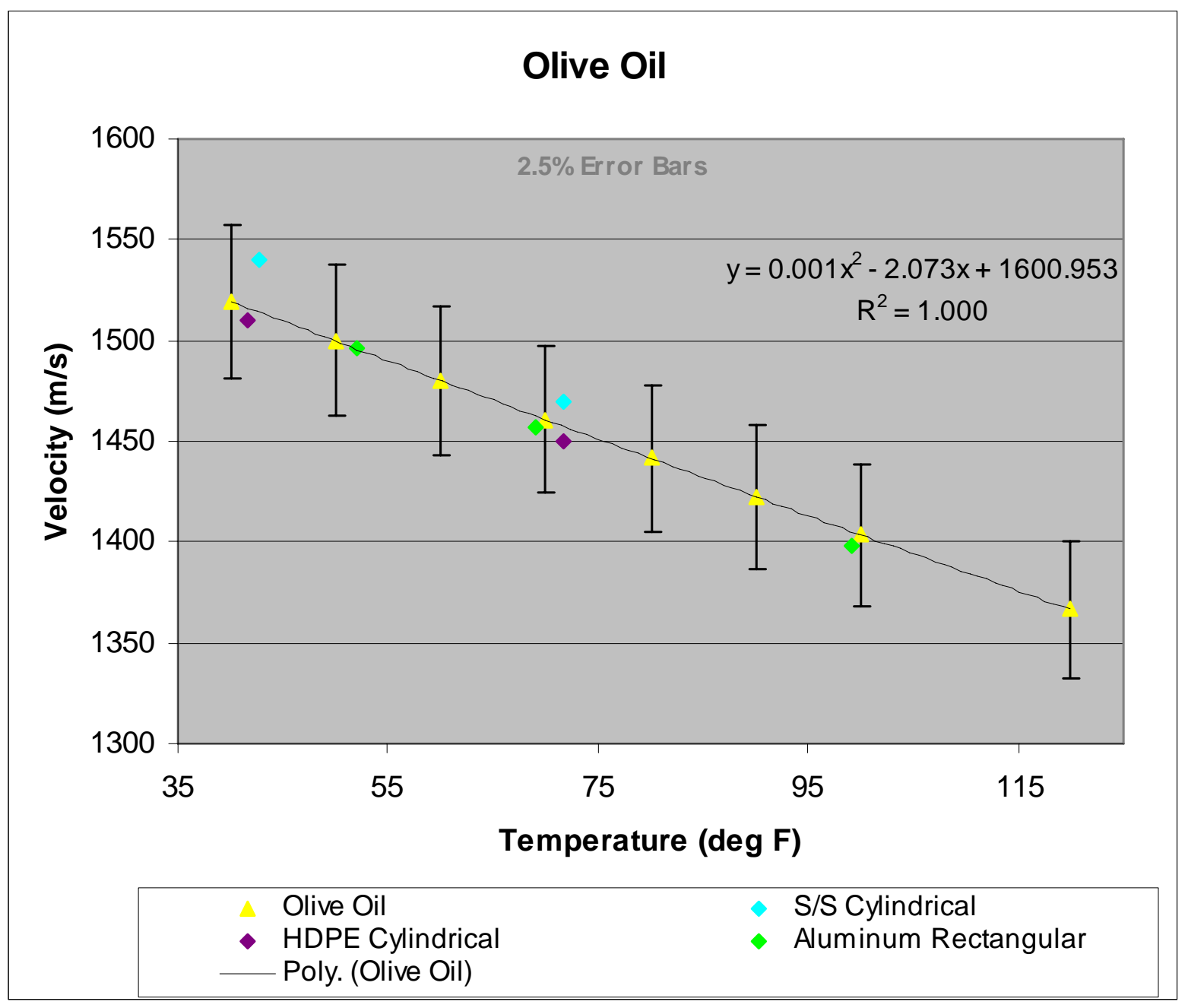

Figure D.1. Validation Points for Olive Oil 


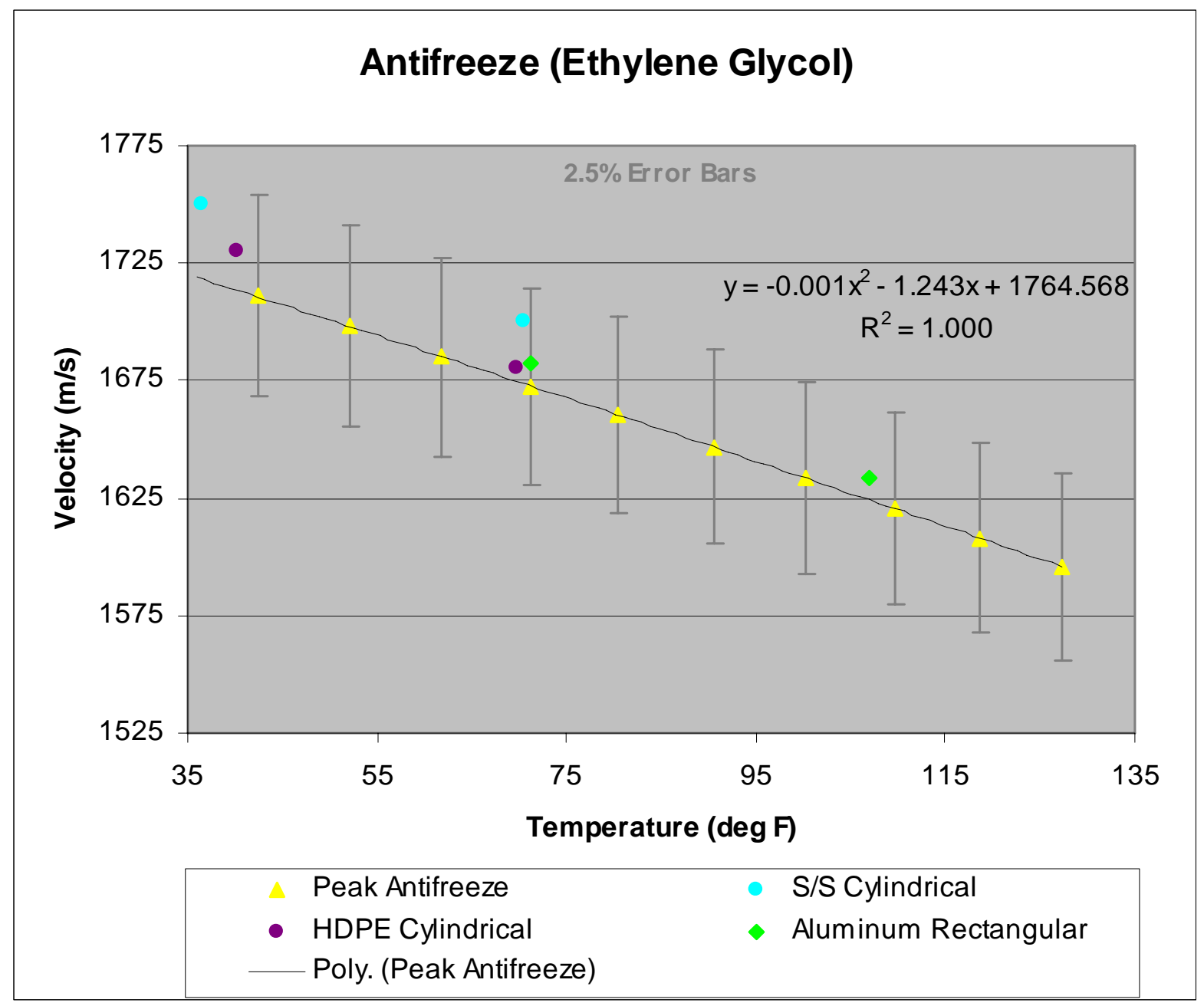

Figure D.2. Validation Points for Antifreeze (Ethylene Glycol) 


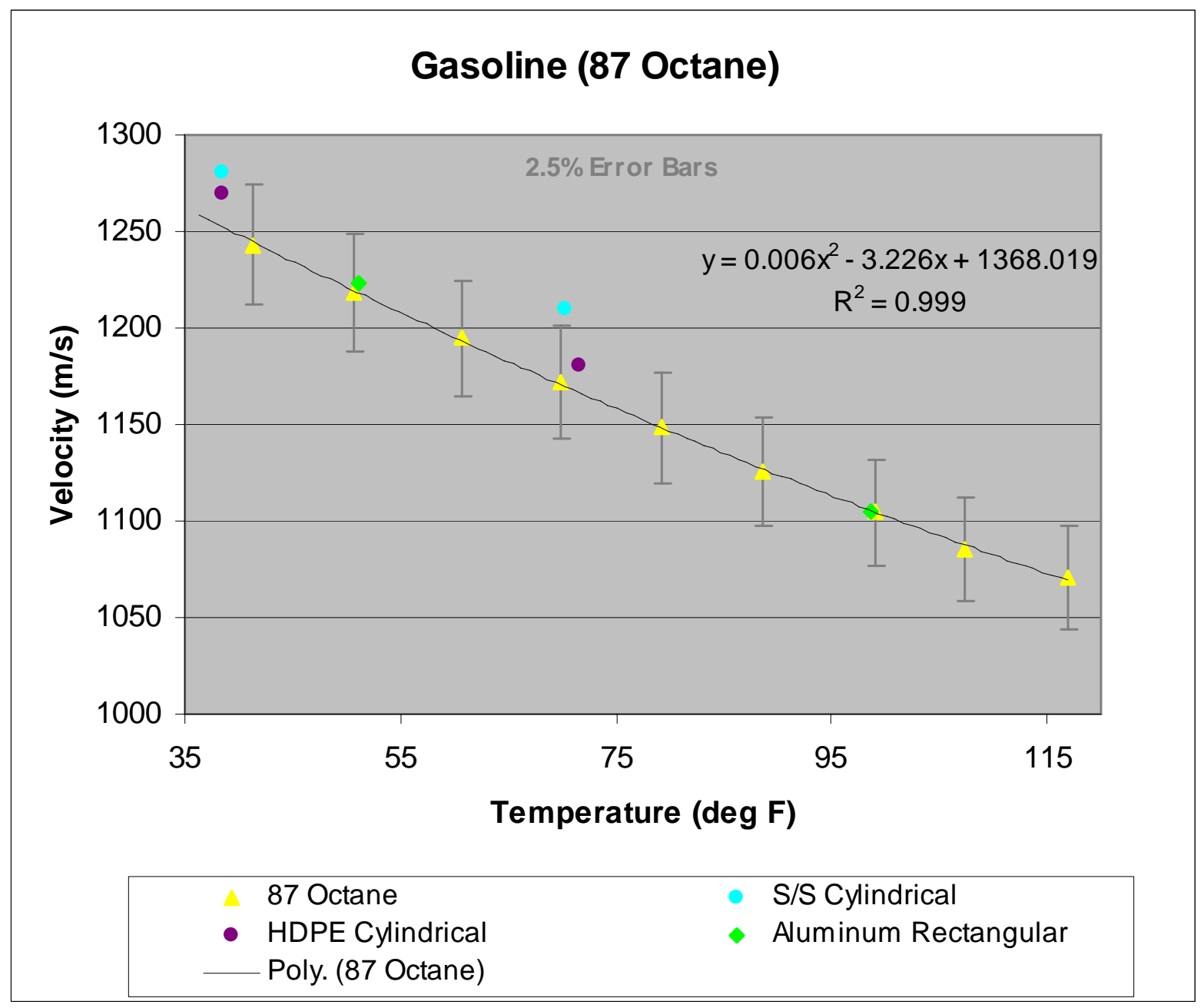

Figure D.3. Validation Points for Gasoline (87 Octane) 


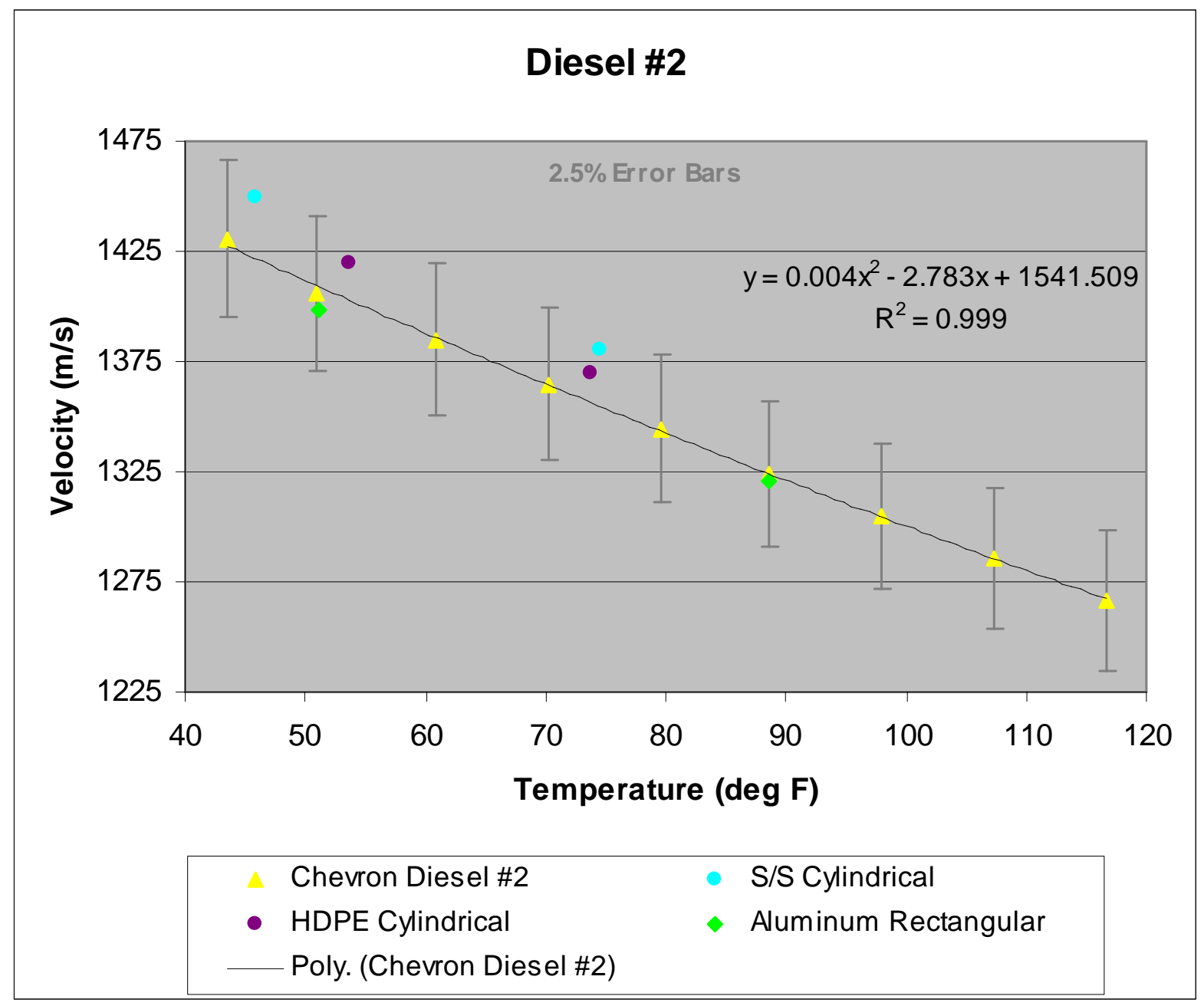

Figure D.4. Validation Points for Diesel No. 2 


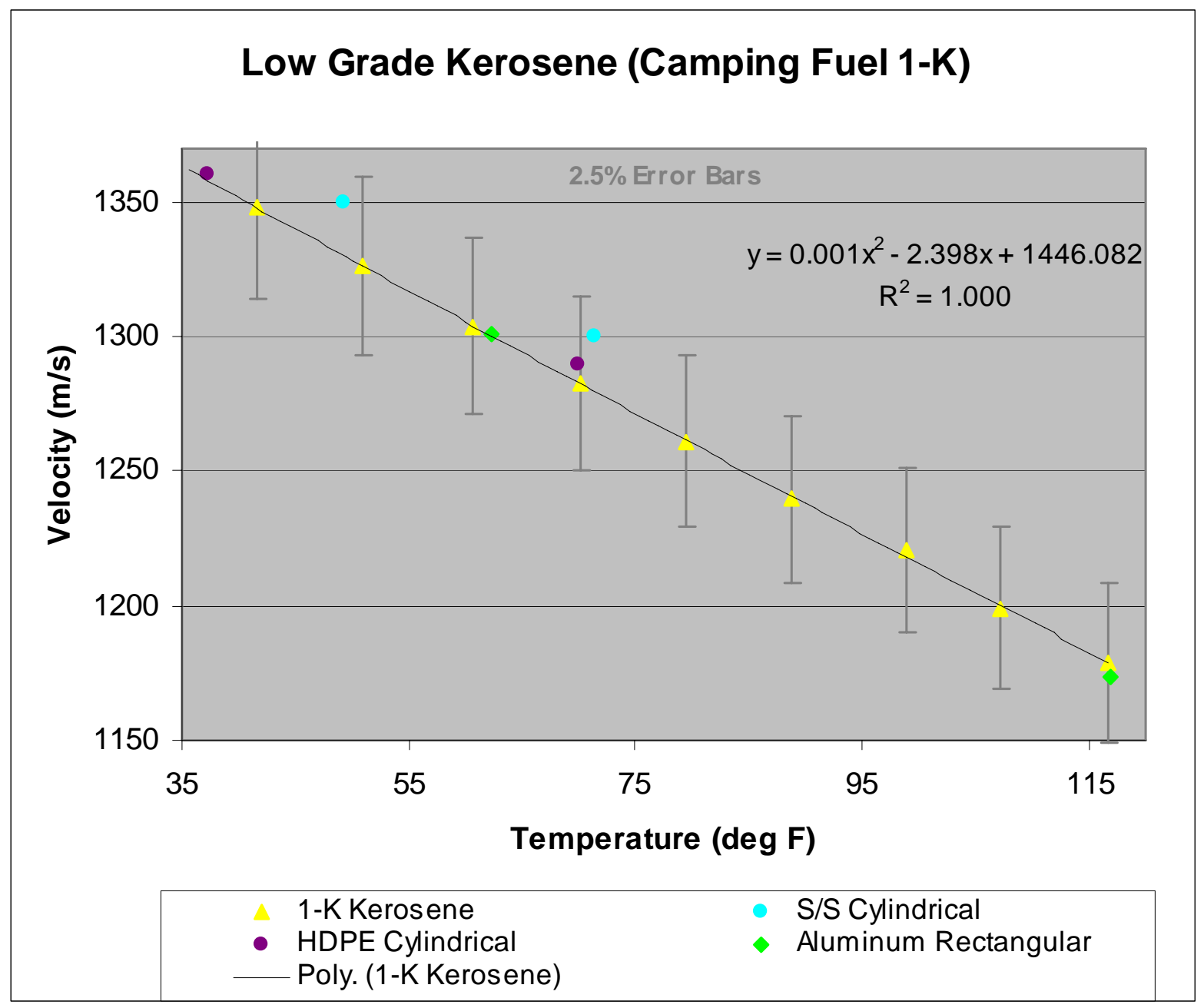

Figure D.5. Validation Points for Low Grade Kerosene (Camping Fuel 1-K) 


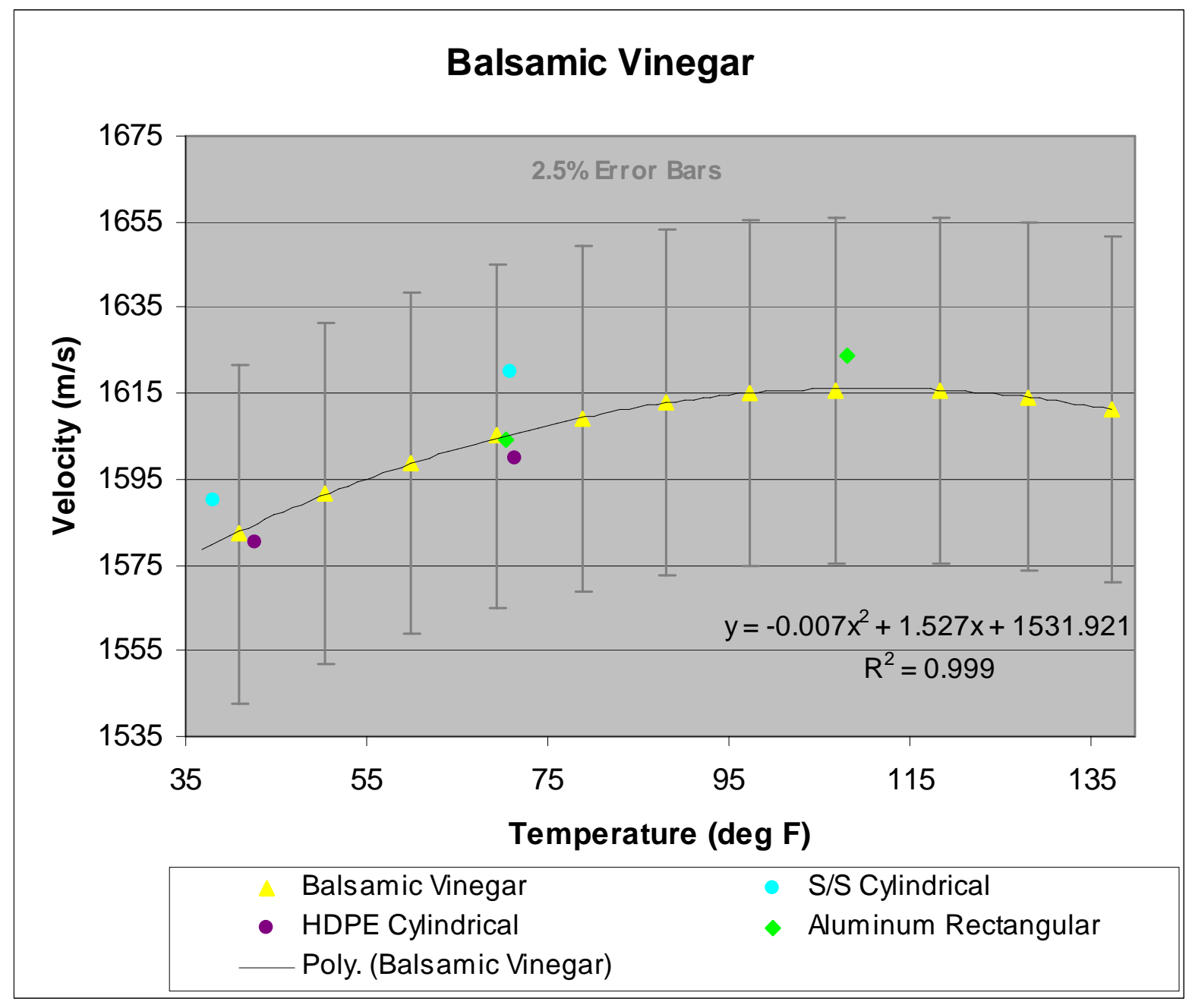

Figure D.6. Validation Points for Balsamic Vinegar 


\section{Liquid Propane}

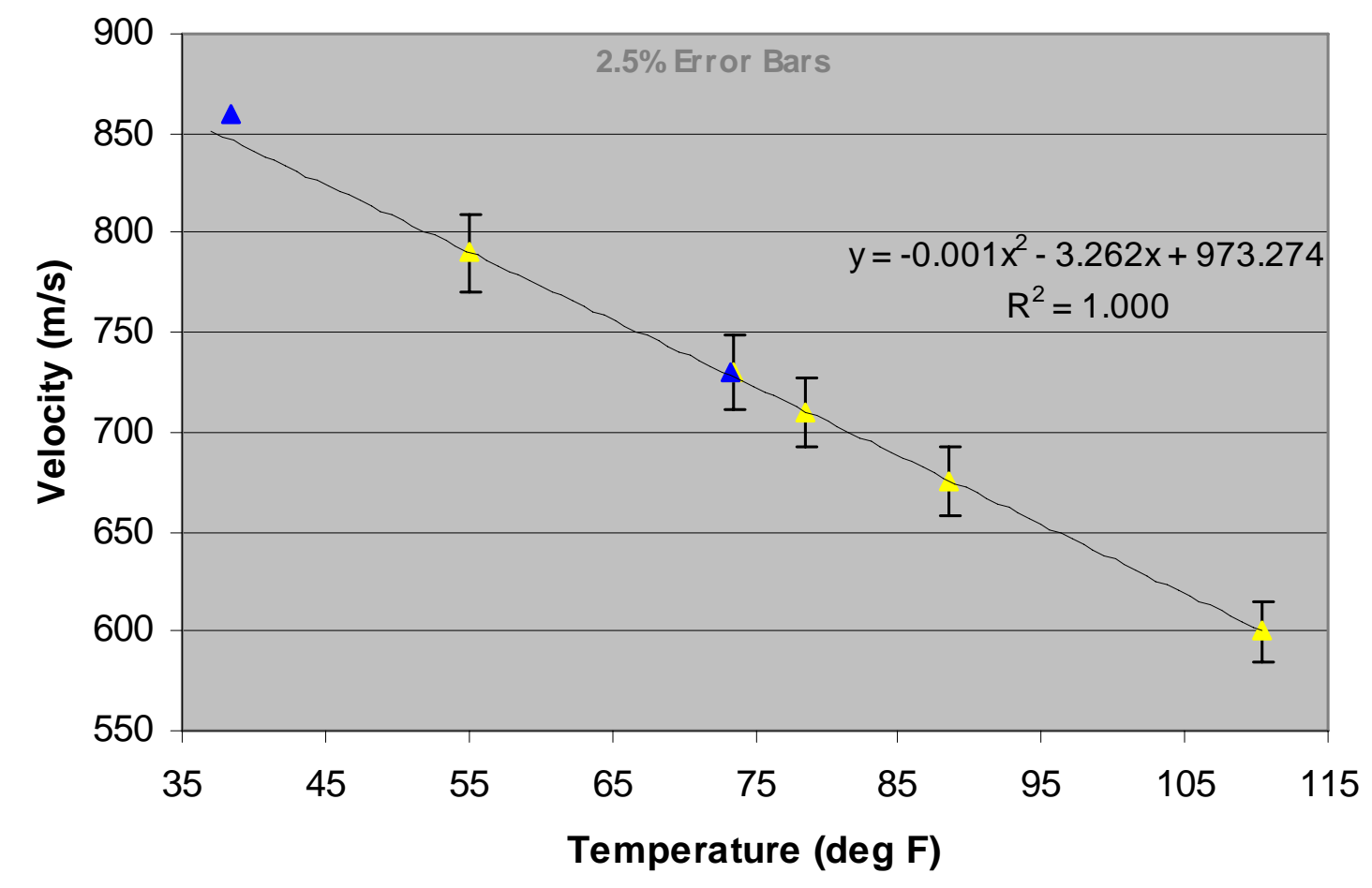

Steel Compressed Gas Cylindrical

- Steel Compressed Gas Cylinder Poly. (Steel Compressed Gas Cylindrical)

Figure D.7. Validation Points for Compressed Liquid Propane 
D. 8 
Appendix E - List of Clients and Participants in Final Phase 1 Activities For TS-00358 



\section{Appendix E - List of Clients and Participants in Final Phase 1 Activities for TS-00358}

SPAWAR Systems Center San Diego Staff Involved:

Robert David George

Ronald David Gauthier

ONR Global - Office of Naval Research (ONR) Staff Involved:

King Phillip Waters

Stephen Carl French Jr.

NAVCENTCOM - US Navy Personnel Involved:

Michael Paul Schilt

Richard R. Muller, Jr.

PNNL Staff Involved:

Aaron Diaz; Kayte Denslow; Todd Samuel; Tony Cinson; Mario Bagaglio

Spearhead Innovations (SI) and International Engineering \& Manufacturing (IE\&M) Staff Involved:

Mary Haller Griffin (SI); Robert Zoltan Frank (SI); Frank A. Russo (IE\&M) 


$$
\text { E. } 2
$$

